\title{
HIV-1 Assembly, Budding, and Maturation
}

\author{
Wesley I. Sundquist ${ }^{1}$ and Hans-Georg Kräusslich ${ }^{2}$ \\ ${ }^{1}$ Department of Biochemistry, University of Utah School of Medicine, Salt Lake City, Utah 84112-5650 \\ ${ }^{2}$ Department of Infectious Diseases, Virology, University of Heidelberg, 69120 Heidelberg, \\ Germany \\ Correspondence:wes@biochem.utah.edu; hans-georg.kraeusslich@med.uni-heidelberg.de
}

\begin{abstract}
A defining property of retroviruses is their ability to assemble into particles that can leave producer cells and spread infection to susceptible cells and hosts. Virion morphogenesis can be divided into three stages: assembly, wherein the virion is created and essential components are packaged; budding, wherein the virion crosses the plasma membrane and obtains its lipid envelope; and maturation, wherein the virion changes structure and becomes infectious. All of these stages are coordinated by the Gag polyprotein and its proteolytic maturation products, which function as the major structural proteins of the virus. Here, we review our current understanding of the mechanisms of HIV-1 assembly, budding, and maturation, starting with a general overview and then providing detailed descriptions of each of the different stages of virion morphogenesis.
\end{abstract}

$\mathrm{T}^{\mathrm{h}}$ he assembling virion packages all of the components required for infectivity. These include two copies of the positive sense genomic viral RNA, cellular tRNA ${ }^{\text {Lys,3 }}$ molecules to prime cDNA synthesis, the viral envelope (Env) protein, the Gag polyprotein, and the three viral enzymes: protease $(\mathrm{PR})$, reverse transcriptase (RT), and integrase (IN). The viral enzymes are packaged as domains within the Gag-Pro-Pol polyprotein, which is generated when translating ribosomes shift into the -1 reading frame at a site near the $3^{\prime}$ end of the gag open reading frame, and then go on to translate the pol gene.

HIV-1 virion assembly occurs at the plasma membrane, within specialized membrane microdomains. The HIV-1 Gag (and Gag-ProPol) polyprotein itself mediates all of the essential events in virion assembly, including binding the plasma membrane, making the protein-protein interactions necessary to create spherical particles, concentrating the viral Env protein, and packaging the genomic RNA via direct interactions with the RNA packaging sequence (termed $\Psi$ ). These events all appear to occur simultaneously at the plasma membrane, where conformational change(s) within Gag couples membrane binding, virion assembly, and RNA packaging. Although Gag itself can bind membranes and assemble into spherical particles, the budding event that releases the virion from the plasma membrane is mediated by the host ESCRT (endosomal sorting complexes required for transport) machinery.

Folded domains within Gag are separated by flexible linker regions which contain the PR

Editors: Frederic D. Bushman, Gary J. Nabel, and Ronald Swanstrom

Additional Perspectives on HIV available at www.perspectivesinmedicine.org

Copyright (C) 2012 Cold Spring Harbor Laboratory Press; all rights reserved; doi: 10.1101/cshperspect.a006924

Cite this article as Cold Spring Harb Perspect Med 2012;2:a006924 
W.I. Sundquist and H.-G. Kräusslich

cleavage sites (Fig. 1B,C). The amino-terminal Gag domain is called MA, and it functions to bind the plasma membrane and to recruit the viral Env protein. The central domain of Gag is called CA, and it mediates the protein-protein interactions required for immature virion assembly and then creates the conical shell (called the capsid) of the mature viral core. The basic Gag NC domain contains two copies of the retroviral zinc finger motif. NC captures the viral genome during assembly, and also functions as a nucleic acid "chaperone" during tRNA $^{\text {Lys,3 }}$ primer annealing and reverse transcription. Finally, the carboxy-terminal Gag p6 region contains binding sites for several other proteins, including the accessory viral protein Vpr, as well as two short sequence motifs, termed "late assembly domains," which bind the TSG101 and ALIX proteins of the cellular ESCRT pathway. Gag also contains two spacer peptides, termed SP1 and SP2, which help to regulate the conformational changes that accompany viral maturation.

The virion acquires its lipid envelope and Env protein spikes as it buds from the plasma membrane. Unlike Gag, Env is an integral membrane protein. It is inserted cotranslationally into ER membranes and then travels through the cellular secretory pathway where it is glycosylated, assembled into trimeric complexes, processed into the trans-membrane (TM; gp41) and surface (SU; gp120) subunits by the cellular protease furin, and delivered to the plasma membrane via vesicular transport.

The Gag polyprotein initially assembles into spherical immature particles, in which the membrane-bound Gag molecules project radially toward the virion interior (Fig. 1D,F). As the immature virion buds, $\mathrm{PR}$ is activated and cleaves Gag into its constituent MA, CA, NC, and $\mathrm{p} 6$ proteins, thereby also releasing the SP1 and SP2 peptides. Proteolysis is required for conversion of the immature virion into its mature infectious form (Fig. 1E,G). Like other retroviral proteases, $\mathrm{HIV}-1 \mathrm{PR}$ is a dimeric aspartic protease (Fig. $1 \mathrm{H}$ ). PR recognizes specific sites within Gag and cleaves them in an ordered fashion (Fig. 1B,C, arrowheads). Gag proteolysis triggers major changes which include condensing and stabilizing the dimeric RNA genome, assembling the conical capsid about the genomic RNA-NC-enzyme complex, and preparing the virion to enter, replicate, and uncoat in the next host cell. Thus, viral maturation can be viewed as the switch that converts the virion from a particle that can assemble and bud from a producer cell into a particle that can enter and replicate in a new host cell. The following sections review our current understanding of HIV-1 assembly, budding, and maturation.

\section{VIRION COMPOSITION AND RNA PACKAGING}

The main constituents of HIV-1 are Gag, which makes up $\sim 50 \%$ of the entire virion mass and the viral membrane lipids, which account for $\sim 30 \%$ of virion mass (reviewed in Carlson 2008). Other viral and cellular proteins together contribute an additional $\sim 20 \%$, whereas the genomic RNA and other small RNAs amount to $\sim 2.5 \%$ of virion mass. Gag, Gag-Pro-Pol, Env, the two copies of genomic RNA, the tRNA primer, and the lipid envelope are all essential for viral replication, whereas the relevance of virion incorporation of other cellular and viral accessory proteins, small RNA molecules, and specific lipids is generally less well understood.

All viral gene products are encoded on the genomic RNA, which also serves as mRNA for Gag and Gag-Pro-Pol, whereas singly or multiply spliced RNAs are translated to produce Env and accessory proteins, respectively. Unspliced and incompletely spliced HIV-1 RNAs are exported from the nucleus via a Rev-dependent export pathway, whereas completely spliced mRNAs exit the nucleus via the normal mRNA export route. Translation of Gag, GagPro-Pol and most accessory proteins occurs on cytosolic polysomes. The two viral membrane proteins, Env and the accessory protein $\mathrm{Vpu}$, which are encoded by the same mRNA, are translated on the rough ER. All virion components need to traffic from their point of synthesis to sites of assembly on the plasma membrane. The coordinated synthesis of structural proteins and enzymes as domains of the Gag and Gag- 
HIV Assembly, Budding, and Maturation

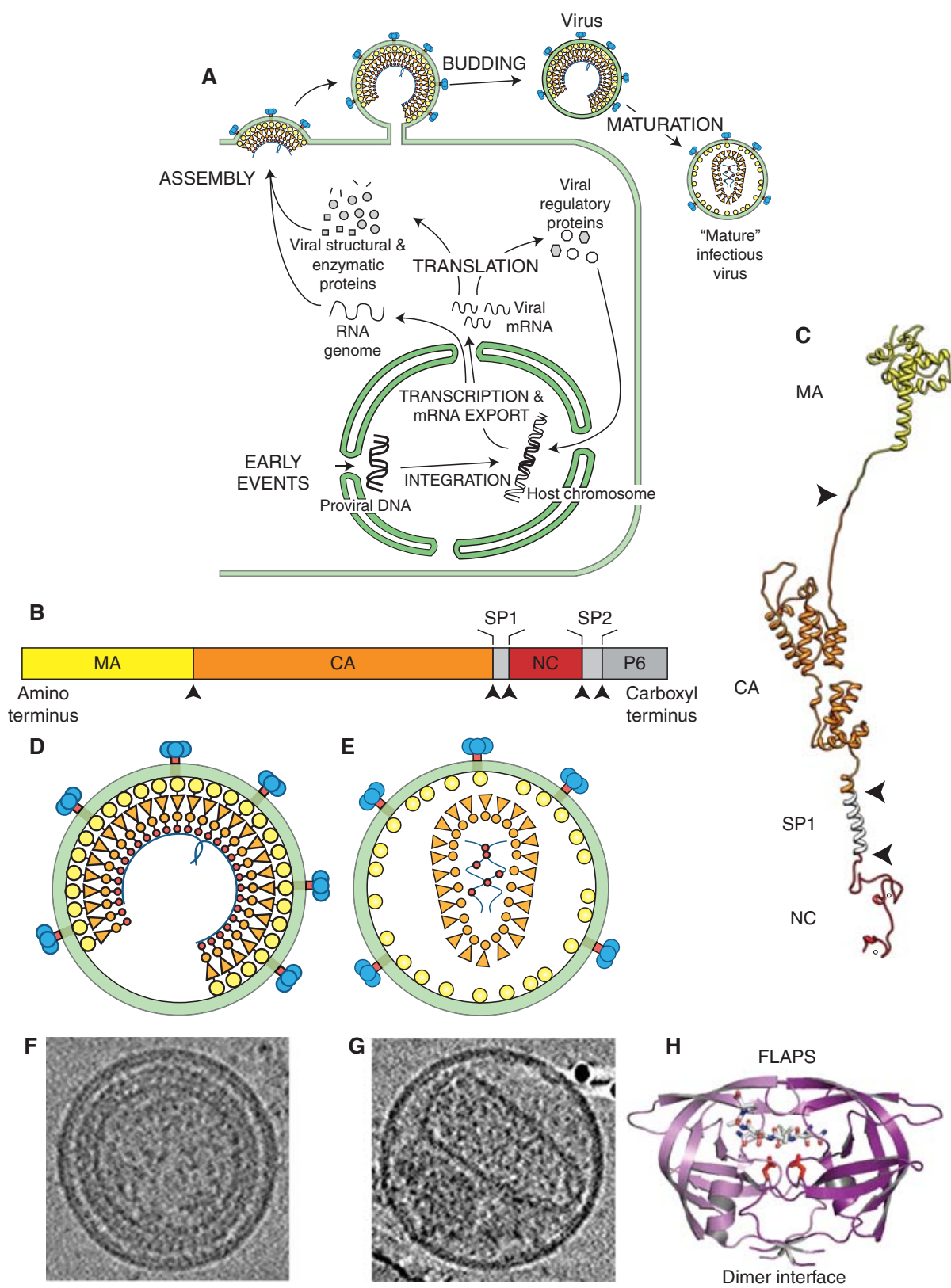

Figure 1. HIV-1 assembly, budding, and maturation. (A) Schematic illustration showing the different stages of HIV-1 assembly, budding, and maturation. (B) Domain structure of the HIV-1 Gag protein; arrows denote the five sites that are cleaved by the viral PR during maturation. $(C)$ Structural model of the HIV-1 Gag protein, created by combining structures of the isolated MA-CA $\mathrm{NTD}_{\mathrm{N}}(2 \mathrm{GOL}), \mathrm{CA}_{\mathrm{CTD}}(1 \mathrm{BAJ})$, and NC (1MFS) proteins, with a helical model for SP1. (D) Schematic model showing the organization of the immature HIV-1 virion. $(E)$ Schematic model showing the organization of the mature HIV-1 virion. (F) Central section from a cryo-EM tomographic reconstruction of an immature HIV-1 virion. ( $G$ ) Central section from a tomographic reconstruction of a mature HIV-1 virion. (H) Structure of HIV-1 protease (PR, 3D3T). The two subunits in the dimer are shown in different shades of purple, the "flap" and dimerization interfaces are labeled, positions of the active site Asp 25 residues are shown in red, and a bound peptide corresponding to the SP2-p6 cleavage site is shown as a stick model, with oxygen atoms in red and nitrogen atoms in blue. 
W.I. Sundquist and H.-G. Kräusslich

Pro-Pol polyproteins (which are produced at a ratio of $\sim 20: 1$ ) ensures that these components are made at the proper stoichiometry (Jacks et al. 1988). Gag then binds other virion components through direct protein-protein and protein-RNA interactions, which allows the virus to assemble all of its components using a single targeting signal (Frankel and Young 1998; Freed 2001).

\section{Protein Trafficking and Virion Incorporation}

The HIV Gag and Gag-Pro-Pol polyproteins traffic from their sites of synthesis in the cytoplasm to the plasma membrane and then sort into detergent-resistant membrane microdomains (Ono and Freed 2001). Virus production is cholesterol and sphingolipid dependent, and the virus is enriched in "raft"-associated proteins and lipids (Ono 2009). Gag has been reported to interact with the cellular motor protein KIF4 (Tang et al. 1999; Martinez et al. 2008) and with various components of intracellular vesicle trafficking pathways (Batonick et al. 2005; Dong et al. 2005; Camus et al. 2007), but the role of microtubules and/or membrane trafficking for Gag membrane transport remains unconfirmed. Gag molecules do not polymerize extensively before they reach the membrane (Kutluay and Bieniasz 2010). Instead, soluble monomeric Gag proteins appear to fold into a compact, auto-inhibited conformation(s), which subsequently undergoes conformational changes that cooperatively couple MA-membrane (see online Movie 1 at www.perspectivesinmedicine.org), NC-RNA, and Gag-Gag interactions (Chukkapalli et al. 2010; Datta et al. 2011a; Jones et al. 2011). Gag molecules thus arrive at the plasma membrane as small oligomers, probably monomers or dimers, which polymerize onto nucleation sites composed of Gag-RNA complexes (Jouvenet et al. 2009). The cellular ATPase, ABCE1, has also been implicated in binding and chaperoning membrane-bound assembly intermediates (Dooher et al. 2007), although mechanistic details remain to be elucidated.

Gag membrane targeting requires myristoylation and a basic patch on the MA domain as well as the plasma membrane-specific lipid phosphatidyl inositol $(4,5)$ bisphosphate $\left(\mathrm{PI}(4,5) \mathrm{P}_{2}\right.$ [Ono et al. 2004]). Binding of the $\mathrm{MA}^{\mathrm{Gag}}$ domain to $\mathrm{PI}(4,5) \mathrm{P}_{2}$ exposes the aminoterminal myristoyl group (Saad et al. 2006, 2007), and this "myristoyl switch" provides an elegant mechanism for anchoring Gag stably on the inner leaflet (Movie 1; Fig. 2). Electrostatic interactions with acidic phospholipids, which are strongly enriched in the HIV-1 lipidome (Brugger et al. 2006), probably also contribute to membrane anchoring. MA domains from other retroviruses can also bind $\mathrm{PI}(4,5) \mathrm{P}_{2}$ (Hamard-Peron et al. 2010), but the energetics of $\mathrm{PI}(4,5) \mathrm{P}_{2}$ binding and myristoyl

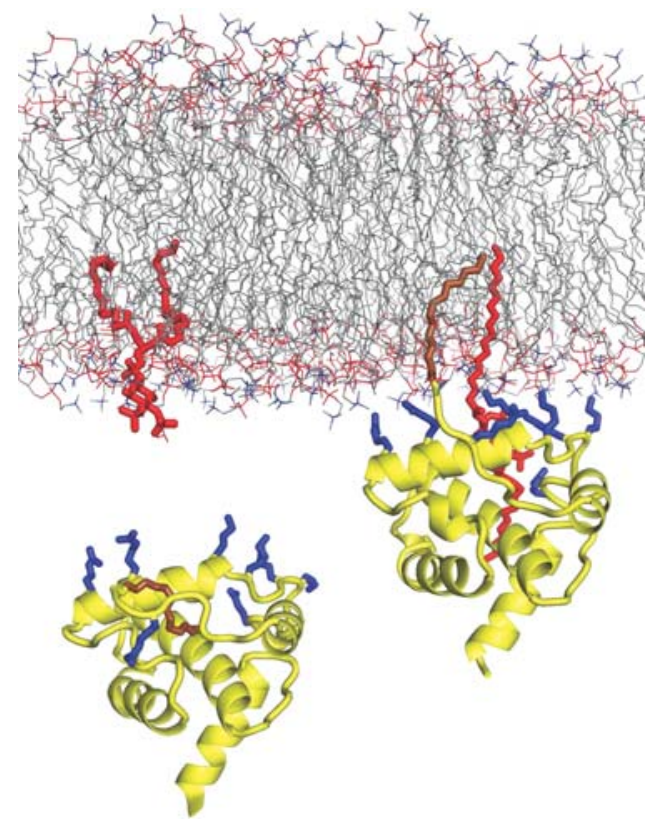

Figure 2. Myristoyl switch model for $\mathrm{MA}^{\mathrm{Gag}}$ recognition of the plasma membrane (Saad et al. 2006). $\mathrm{MA}^{\text {Gag }}$ (yellow) proteins are shown with the aliphatic myristoyl group (brown) sequestered within the soluble protein (left, $1 \mathrm{UPH}$ ), and with the myristoyl group extruded into the membrane when bound to the plasma membrane specific phosphatidyl inositide, $\mathrm{PI}(4,5) \mathrm{P}_{2}$, shown in red (right, $\left.2 \mathrm{H} 3 \mathrm{~F}\right)$. The $\mathrm{PI}(4,5) \mathrm{P}_{2}$ inositol head group and unsaturated $2^{\prime}$-fatty acid bind within MA, allosterically inducing extrusion of the myristoyl group, whereas the saturated $1^{\prime}$-fatty acid of $\mathrm{PI}(4,5) \mathrm{P}_{2}$ remains embedded in the membrane. Basic residues on the membrane binding surface of $\mathrm{MA}^{\mathrm{Gag}}$ are shown in blue. 
HIV Assembly, Budding, and Maturation

sequestration vary, and not all retroviral MA proteins have amino-terminal myristoyl groups, suggesting that additional factors may govern membrane targeting, at least in those cases (Saad et al. 2008; Inlora et al. 2011).

The viral Env glycoproteins reach the plasma membrane independently of Gag. Genetic and biochemical analyses indicate that the long intracellular tail of TM helps sort Env into "raft"-like domains and mediates specific interactions with $\mathrm{MA}^{\mathrm{Gag}}$ that promote Env virion incorporation ( $\mathrm{Yu}$ et al. 1993; Cosson 1996; Murakami and Freed 2000; Wyma et al. 2000). Deletion of the TM cytoplasmic tail abolishes viral infectivity in most cell lines, but does not prevent Env incorporation (Einfeld 1996). Moreover, virions can be efficiently pseudotyped by heterologous glycoproteins without specific HIV-1 Gag interactions (Briggs et al. 2003a), implying that the MA-Env interaction is not absolutely essential for Env incorporation. Interestingly, pseudotyped particles seem to segregate into distinct classes, apparently displaying only one or the other glycoprotein (Leung et al. 2008). HIV-1 displays only 714 glycoprotein trimers per virion (Chertova et al. 2002; Zhu et al. 2006). This number is considerably lower than for the related simian immunodeficiency virus, which has approximately 80 Env trimers per virion (Zhu et al. 2006), and suggests that clustering of the sparsely distributed Env trimers may be important for HIV-1 entry (Sougrat et al. 2007). Other constituents of the virion are the accessory protein Vpr (incorporated at a ratio of 1:7 to Gag [Muller et al. 2000]) through a specific interaction with the p6 domain (Kondo et al. 1995) as well as a few copies of the accessory proteins Vif and Nef.

Analysis of purified virion preparations by immunoblotting or mass spectroscopy has identified many cellular proteins in HIV-1 particles (Ott 2008), but their importance for virus assembly, budding, and/or infectivity is currently not well established in most cases. These cellular proteins include plasma membrane proteins like ICAM-1 (which may mediate virus adherence to cells) and HLA-II (which may modulate immune responses), as well as cytoplasmic proteins which may be incorporated via direct or indirect Gag interactions (e.g., actin and actin-binding proteins, cyclophilin A, ubiquitin, lysyl-tRNA-synthetase, and many RNAbinding proteins [Ott 2008]).

\section{Viral Lipid Composition}

HIV-1 buds at the plasma membrane of infected cells and the viral membrane is therefore derived from the cellular plasma membrane. Aloia et al. $(1988,1993)$ initially reported differences between the lipid compositions of the producer cell and HIV-1 membranes, with virion enrichment of sphingomyelin (SM), phosphatidyl serine (PS), phosphatidyl ethanol (PE), and cholesterol, as well as decreased membrane fluidity. Recent advances in lipid mass spectrometry have allowed a comprehensive, quantitative analysis of the entire lipid composition (the lipidome) of purified HIV-1 including determination of side chains. These analyses revealed strong virion enrichment of the "raft lipids" SM, cholesterol, and plasmalogen-PE, with an increase in saturated fatty acids compared with the producer cell membrane. The inner leaflet of the viral membrane is enriched in PS, and the overall lipid composition of HIV-1 strongly resembles detergent-resistant membranes isolated from producer cells (Brugger et al. 2006). The native HIV-1 membrane exhibits a liquid-ordered structure (Lorizate et al. 2009), providing further evidence for its raft-like nature. The HIV-1 membrane is also enriched in $\mathrm{PI}(4,5) \mathrm{P}_{2}$, consistent with the idea that this phosphatidylinositide plays an important role in targeting Gag to the membrane (Chan et al. 2008; also see above). Membranes of the murine leukemia virus are also enriched in cholesterol, ceramide, and glycosphingolipids (Chan et al. 2008), indicating that other retroviruses also bud from raft-like membrane domains.

\section{RNA Trafficking and Incorporation}

HIV-1, like all retroviruses, selectively incorporates two copies of the capped and polyadenylated full-length RNA genome into the virion 
W.I. Sundquist and H.-G. Kräusslich

(Johnson and Telesnitsky 2010; Lever 2007). The two RNA strands are noncovalently dimerized in their 5'UTR. RNA dimerization initiates through formation of a "kissing-loop" structure mediated by Watson-Crick base pairing of the self-complementary sequence within the loop of the dimer initiation site (DIS) (Fig. 3), which then expands into a more extended helix linkage during viral maturation. RNA dimerization is required for RNA packaging and viral infectivity (Moore and $\mathrm{Hu}$ 2009), and involves cisacting sequences within the $5^{\prime} \mathrm{UTR}$ of the viral genome, which are recognized by the $\mathrm{NC}^{\mathrm{Gag}}$ domain. RNA-Gag interactions also appear to convert the compact, auto-inhibited Gag conformation into its extended assembly conformation which is required for virus assembly (Rein et al. 2011). Removal of the RNA packaging signal does not abolish particle production, but the resulting particles do contain abnormally high levels of nonspecific cellular mRNAs (Rulli et al. 2007), implying that RNA facilitates virion assembly by concentrating and aligning Gag molecules at the plasma membrane.

Although NC can bind RNA nonspecifically, genome packaging requires specific recognition of the dimeric, unspliced HIV-1 RNA. Recent single virion analyses by fluorescence microscopy have confirmed that nearly all HIV-1 particles contain genomic RNA, which is dimeric in most cases (Chen et al. 2009). Efficient genome packaging depends on a structural element of approximately 150 nucleotides located in the $5^{\prime}$ region spanning the major splice donor and the Gag initiation codon (the $\Psi$-site) (D'Souza and Summers 2005). The requirements for elements located downstream from the first splice donor explain why unspliced viral RNA is selectively packaged, at least in the case of HIV- 1 . The $\Psi$-site comprises four stable stem loop structures within the highly structured 5'UTR (Fig. 3), but efficient genome packaging appears to be affected by almost the entire $5^{\prime} \mathrm{UTR}$, particularly elements close to the DIS. Structural analyses of individual loops from the $\Psi$-site in complex with NC revealed specific interactions between the CCHC-type zinc knuckles of $\mathrm{NC}$ and exposed loop residues of the RNA (Fig. 3), providing insight into the

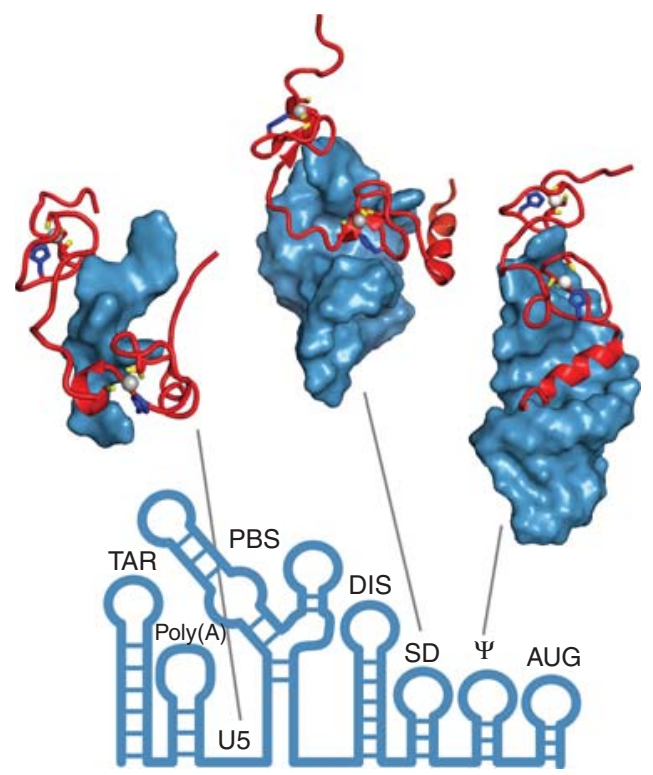

Figure 3. $5^{\prime}$ Untranslated region (UTR) of the HIV-1 RNA genome and its interactions with the viral NC protein. Lower image shows a secondary structure model for the $5^{\prime} \mathrm{UTR}$, highlighting the TAR stem loop structure (which binds the viral Tat protein), the polyadenylation site, the U5 element, the primer binding site (PBS, which anneals to the tRNA ${ }^{\mathrm{Lys}, 3}$ primer), and four stem loops within the packaging site, which contain the dimer initiation site (DIS, stem-loop I, which forms a kissing loop structure that initiates association of the two copies of the genomic RNA), the splice donor (SD, stem loop II, which acts as the $5^{\prime}$ donor for splicing of subgenomic RNAs), the Psi site ( $\psi$, stem loop III, which forms an essential part of the packaging signal), and the Gag start codon (AUG, stem loop IV, which contains the start site for Gag translation). Upper structures show three different complexes between the NC protein (red, with zinc atoms shown in grey and Zn-coordinating side chains shown explicitly) and viral RNAs (blue), corresponding to the U5 region (Spriggs et al. 2008), the SD stem loop (1F6U), and the $\psi$ stem loop (1A1T).

mechanism of RNA recognition (see online Movie 2 at www.perspectivesinmedicine.org). The structural basis of dimeric RNA packaging is best understood for the genome of murine leukemia virus, where the highaffinity $\mathrm{NC}$ binding sites are sequestered and become exposed only upon RNA dimerization 
HIV Assembly, Budding, and Maturation

(Miyazaki et al. 2010). Retroviruses can copy information from either of their two packaged RNA strands during reverse transcription. This "pseudodiploid" property confers the distinctive advantage of high recombination potential and helps retroviruses to overcome environmental and therapeutic pressures.

Gag polyproteins of avian and murine retroviruses and of foamy virus reportedly enter the nucleus, where they bind newly transcribed RNA and cotraffic to sites of assembly (Schliephake and Rethwilm 1994; Scheifele et al. 2002; Andrawiss et al. 2003). Nuclear import and export has also been suggested for HIV-1 Gag (Dupont et al. 1999), but productive Gag-RNA packaging interactions appear to occur in the cytoplasm in this case. A cell fusion-dependent recombination assay was used to show that HIV-1 RNA dimerization, which is essential for packaging, occurs in the cytoplasm (Moore et al. 2009), and that dimerization frequency depends on the complementarity of the DIS loop sequences (Fig. 3). Overall, current data support a model in which genomic RNA dimerizes and associates with a few Gag molecules in the cytoplasm. These RNP complexes then traffic to the plasma membrane where they nucleate assembly (Kutluay and Bieniasz 2010).

In addition to the viral genome, HIV-1 particles also package small cellular RNAs, most notably tRNAs required for the initiation of reverse transcription (Kleiman et al. 2010). Two copies of tRNA ${ }^{\text {Lys3 }}$ anneal via WatsonCrick base pairing to an 18 base-pair sequence known as the primer binding sites (PBS), which is located within the $5^{\prime}$ LTR (Fig. 3). The tRNA $^{\text {Lys1,2 }}$ isoacceptors are also selectively packaged, and it has been suggested that GagPro-Pol, genomic RNA, and lysyl-tRNA synthetase are all involved in specific tRNA packaging (Kleiman et al. 2010). HIV-1 particles also contain 7SL, the RNA component of host signal recognition particle (SRP), at a sevenfold molar excess over genomic RNA (Onafuwa-Nuga et al. 2006). However, SRP protein constituents are not incorporated and the functional significance of 7SL incorporation is unknown. Other RNA constituents of the virion include the 5S,
$18 \mathrm{~S}$, and $28 \mathrm{~S}$ rRNAs, which may simply be present owing to their cytoplasmic abundance.

\section{HIV ASSEMBLY AND THE IMMATURE LATTICE}

Direct visualization of individual budding and release events at high temporal resolution using fluorescently labeled Gag polyproteins and live-cell microscopy has recently revealed the kinetics of HIV-1 assembly and host cell factor recruitment (Jouvenet et al. 2008; Ivanchenko et al. 2009). Furthermore, live-cell fluorescence imaging revealed cytoplasmic genomic RNA to be highly dynamic in the absence of Gag, whereas a fraction of RNA molecules became immobilized at specific sites at the plasma membrane upon coexpression of Gag (Jouvenet et al. 2009). These sites marked the position of subsequent assembly events in most cases. Gag levels increase exponentially at individual plasma membrane assembly sites until a plateau is reached and budding ensues. The mean assembly time for individual particles is $\sim 10$ min, albeit with significant variability between sites (Jouvenet et al. 2008; Ivanchenko et al. 2009). Assembling Gag molecules are largely derived from the rapidly diffusing cytoplasmic pool (Ivanchenko et al. 2009) and do not enter via lateral diffusion within the membrane or from vesicle-associated Gag transport.

Gag assembly leads to formation of the immature lattice. Immature particles have historically been studied using virions that lacked PR activity or using virus-like particles assembled in vitro from bacterially expressed Gag proteins. However, recent direct imaging of budding viruses has confirmed that the immature Gag lattice is established as the virus assembles (Fig. 4A; Carlson et al. 2010). The Gag molecules in the immature virion are extended and oriented radially, with their amino-terminal MA domains bound to the inner membrane leaflet and their carboxyterminal p6 domains facing the interior of the particle (Fig. 4B; Fuller et al. 1997). The immature lattice is stabilized primarily by lateral protein-protein interactions involving the CA-SP1 region, with the carboxy-terminal domain of 

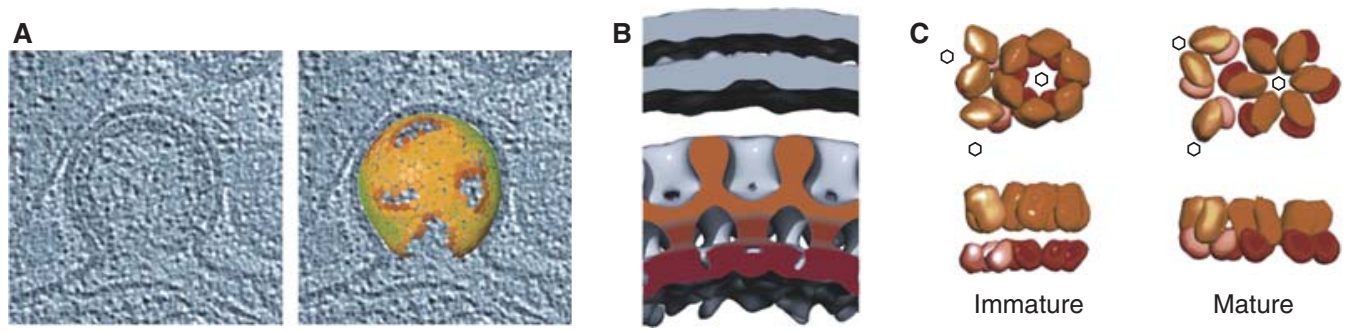

Mature

Figure 4. Assembly and structure of immature HIV-1 particles. (A) (Left) Central slice through a cryo-EM tomogram of a budding HIV-1 virion. (Right) Map of the Gag lattice in the budding virion. Positions of Gag hexagons are colored according to their hexagonal order, from low (brown) to high (green). (B) Cryo-EM tomogram of an immature HIV-1 virion, showing the structure of the immature HIV-1 Gag lattice. The surface was cut perpendicular to the membrane to reveal the two membrane leaflets, the two CA domains (orange and burnt orange), and the NC layer (red). (C) Schematic of the conformational rearrangements in the capsid lattice during maturation. (Left) Arrangement of the amino-terminal (orange) and carboxy-terminal (burnt orange) domains of CA in the immature lattice, viewed from outside the particle (upper), and rotated $90^{\circ}$ around the horizontal axis (lower). Domains from neighboring hexamers are indicated in lighter colors, and sixfold lattice positions are marked by hexagons. (Right) Equivalent interactions of CA subunits within the mature HIV-1 capsid lattice.

CA ( CA $\left._{\text {CTD }}\right)$ and SP1 making particularly important interactions (Fig. 4B). MA and NC help to align and concentrate Gag molecules, but MA and p6 are dispensable for immature lattice formation, and $\mathrm{NC}$ can be replaced by a heterologous protein dimerization domain (Zhang et al. 1998; Accola et al. 2000). Extensive mutational analyses have identified the contributions of individual residues to immature and mature particle assembly (e.g., von Schwedler et al. 2003). These studies have generally confirmed the critical importance of the CA $\mathrm{A}_{\mathrm{CTD}}$ and $\mathrm{SP} 1$ regions for immature particle assembly, and in particular of the "major homology region" within $\mathrm{CA}_{\mathrm{CTD}}$ which is conserved across retroviruses.

Over the past few years, cryoelectron tomography and image processing analyses have defined the three-dimensional structure of the immature Gag lattice in greater detail (Wright et al. 2007; Briggs et al. 2009). These studies confirmed that Gag molecules are arranged as hexamers with $8 \mathrm{~nm}$ spacings (Fig. 4). The $\mathrm{CA}_{\mathrm{NTD}}$ forms six-membered rings with large central holes (Fig. 4B). At the current resolution $(\sim 2 \mathrm{~nm})$, high-resolution structures cannot be unequivocally positioned within the density maps, but the lattice does not appear to be consistent with hexameric arrangements seen in crystallographic studies of the murine leukemia virus $\mathrm{CA}_{\mathrm{NTD}}$ (Mortuza et al. 2004). Density for the $\mathrm{CA}_{\mathrm{CTD}}$ domain resides beneath the hexamers, and the domain appears to make both intraand interhexameric contacts (Fig. 4B and C). Like the full-length $\mathrm{CA}$ protein, $\mathrm{CA}_{\mathrm{CTD}}$ constructs dimerize in solution and several different high-resolution $\mathrm{CA}_{\text {СТD }}$ structures have been reported, two of which appear to be used in constructing the mature capsid lattice (see below). Two other $\mathrm{CA}_{\text {CTD }}$ dimer structures have been suggested to play a role in stabilizing the immature lattice: a domain-swapped dimer (Ivanov et al. 2007) in which the MHR elements from each monomer associate to create a large interface, and a $\mathrm{CA}_{\mathrm{CTD}}$ dimer observed in the presence of a peptide assembly inhibitor (CAI) or for certain mutations in the CAI binding pocket (Ternois et al. 2005; Bartonova et al. 2008). The CAI-induced dimer appeared to be the best fit to the reconstructed EM density, but it is currently unclear whether any of the $\mathrm{CA}_{\mathrm{CTD}}$ dimer structures is actually reconstituted within the immature lattice, and higher resolution structures of immature particles are eagerly awaited.

Residues at the carboxy-terminal end of CA and in the adjacent SP1 region are also essential for immature lattice formation, and this region has been suggested to form a continuous $\alpha$ helix 
HIV Assembly, Budding, and Maturation

(Accola et al. 1998). This model is consistent with tomographic reconstructions of the immature lattice, which revealed rod-like structures descending toward the NC layer along the sixfold symmetry axis below $\mathrm{CA}_{\mathrm{CTD}}$ (Fig. 4B; Wright et al. 2007). These features can be modeled as six helix bundles, although this model again awaits definitive testing at higher resolution. Interestingly, the helical propensity of the CA-SP1 junction sequence is rather weak (Morellet et al. 2005), but recent evidence suggests that helix formation is strongly induced by molecular crowding (Datta et al. 2011b). Thus, helix formation could provide a switch that helps trigger immature lattice formation as the Gag molecules coalesce (Datta et al. 2011b). Subsequent proteolytic cleavage at the CA-SP1 junction would then destroy the helix during maturation, destabilize immature lattice interactions, and help drive conversion to the mature capsid lattice.

In addition to defining the structure of Gag hexamers, the cryo-EM tomographic studies revealed how the hexameric lattice curves into a spherical structure. A perfect hexagonal lattice lacks declination, and must therefore include nonhexameric defects in order to enclose space. In the mature capsid, this is achieved by including 12 pentameric defects (see below). In contrast, the immature lattice contains small, irregularly shaped defects and holes that permit it to curve (Fig. 4A; Briggs et al. 2009). Nevertheless, the Gag shell forms a contiguous lattice rather than consisting of smaller "islands" of regular Gag arrays. It does contain one large gap, however, which covers approximately onethird of the surface area of the membrane (Wright et al. 2007; Briggs et al. 2009). This gap in the Gag lattice is created when the virus buds (Fig. 4A), because Gag assembly and budding appear to be competitive processes, and immature virions typically bud before the Gag molecules have finished polymerizing into fully closed shells (Carlson et al. 2010). As a result of this gap, virions contain fewer Gag molecules than was initially calculated based on the assumption of a complete virus shell. The precise number of Gag molecules depends on the size of the individual virion and the completeness of the Gag shell, with a virion of $130 \mathrm{~nm}$ diameter containing roughly 2500 Gag molecules (Carlson et al. 2008).

\section{HIV BUDDING}

\section{Late Domains and ESCRT Pathway Recruitment}

Although the viral Gag protein is responsible for cofactor packaging and virion assembly, the virus usurps the host ESCRT pathway to terminate Gag polymerization and catalyze release (Morita and Sundquist 2004; Bieniasz 2009; Carlton and Martin-Serrano 2009; Usami et al. 2009; Hurley and Hanson 2010; Peel et al. 2011). ESCRT factors also catalyze the topologically equivalent membrane fission reactions that release vesicles into endosomal multivesicular bodies (Hurley and Hanson 2010; Peel et al. 2011) and that separate daughter cells during the abscission stage of cytokinesis (Carlton and Martin-Serrano 2007, 2009; Hurley and Hanson 2010; Elia et al. 2011; Guizetti et al. 2011; Peel et al. 2011). This ability of the ESCRT machinery to facilitate membrane fission from within the necks of thin, cytoplasm-filled membrane vesicles and tubules explains why HIV-1, and many other enveloped viruses, have evolved to use the pathway to bud from cells.

HIV-1 p6 $6^{\mathrm{Gag}}$ contains two different "late domain" motifs that bind and recruit early-acting ESCRT factors (Morita and Sundquist 2004; Bieniasz 2009; Carlton and Martin-Serrano 2009; Usami et al. 2009). The primary "PTAP" late domain binds the TSG101 subunit of the heterotetrameric ESCRT-I complex (Garrus et al. 2001; Martin-Serrano et al. 2001; VerPlank et al. 2001; Demirov et al. 2002; Morita and Sundquist 2004; Bieniasz 2009). Each of the four residues (Pro-Thr/Ser-Ala-Pro) makes specific contacts within an extended groove on the amino-terminal ubiquitin E2 variant (UEV) domain of TSG101 (Pornillos et al. 2002; Im et al. 2010). PTAP motifs are also found within HRS and related proteins that recruit ESCRT to endosomal membranes (Ren and Hurley 2011). Thus, the HIV-1 p6 ${ }^{\text {Gag }}$ PTAP late domain mimics a cellular ESCRT-I 
W.I. Sundquist and H.-G. Kräusslich

recruiting motif, and Gag and HRS can both be viewed as membrane-specific adaptors for the ESCRT pathway (Pornillos et al. 2003).

The second $\mathrm{p} 6^{\mathrm{Gag}}$ late domain, designated "YPXL" (Tyr-Pro-X-Leu, where "X" can vary in sequence and length), binds the ESCRT factor ALIX (Strack et al. 2003; Usami et al. 2009). The YPXL late domain contributes significantly to HIV-1 replication (Fujii et al. 2009; Eekels et al. 2011) but is less critical than the PTAP motif in most cell types. Retroviral YPXL late domains exhibit considerable sequence variation, but a conserved tyrosine binds deep within a pocket on the second arm of the ALIX V domain in all cases, and downstream hydrophobic residues contact ALIX along a shallow adjacent groove (Zhai et al. 2008, 2011). Once again, the virus is mimicking a motif used by cellular ALIX ligands in fungi (Vincent et al. 2003), although YPXLcontaining binding partners for mammalian ALIX proteins remain to be characterized. The amino-terminal ALIX Bro domain also interacts with $\mathrm{NC}^{\mathrm{Gag}}$, and NC mutants can exhibit budding defects, reflecting the apparent functional importance of this interaction (Popov et al. 2008, 2009; Dussupt et al. 2009). Finally, the carboxy-terminal domain of $\mathrm{CA}^{\mathrm{Gag}}$ interacts with NEDD4L, a member of the human NEDD4 ubiquitin E3 ligase protein family (Chung et al. 2008; Usami et al. 2008; Weiss et al. 2010). Although this interaction contributes only modestly to HIV-1 budding, NEDD4 family members play critical roles in the budding of other retroviruses through direct interactions with their PPXY (Pro-Pro-X-Tyr) late domains (Morita and Sundquist 2004; Bieniasz 2009; Carlton and Martin-Serrano 2009; Usami et al. 2009).

\section{Assembly of the Core ESCRT Machinery}

The human ESCRT pathway comprises more than 30 different proteins, and this complexity is expanded further by associated regulatory and ubiquitylation machinery. Essential ESCRT pathway functions and mechanisms are conserved across eukaryotes and archaea, and many basic principles have been elucidated through biochemical and genetic analyses of the simpler yeast pathway (Saksena et al. 2007; Hurley and Hanson 2010). Recent functional studies have identified a minimal core set of human ESCRT machinery that is essential for HIV-1 budding (Fig. 5). In essence, TSG101/ ESCRT-I and ALIX both function by recruiting downstream ESCRT-III and VPS4 complexes, which in turn mediate membrane fission and ESCRT factor recycling (Morita and Sundquist 2004; Bieniasz 2009; Carlton and MartinSerrano 2009; Hurley and Hanson 2010; Peel

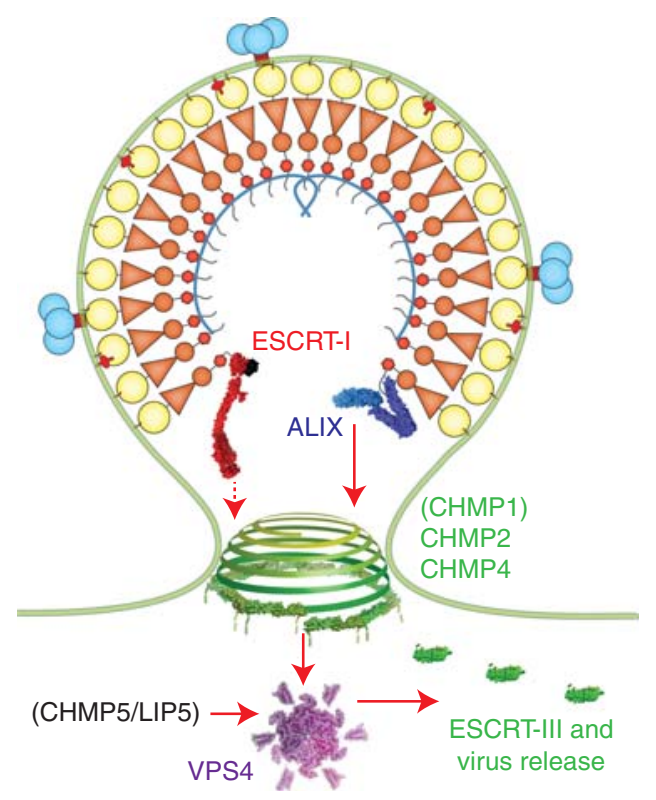

Figure 5. Summary of the essential core ESCRT machinery used in HIV-1 budding (with auxiliary factors shown in parentheses), illustrating a leading model for the budding mechanism. Late domain motifs within $\mathrm{p} 6^{\mathrm{Gag}}$ bind directly to the UEV domain of the TSG101 subunit of the heterotetrameric ESCRT-I complex (red, with bound ubiquitin in black, 1S1Q, 2P22) and the V domain of ALIX (blue, 2OEV). These interactions result in the recruitment of the ESCRT-III proteins of the CHMP1, CHMP2, and CHMP4 families (green, 2GD5), which apparently polymerize into a "dome" that promotes closure of the membrane neck (Peel et al. 2011). They also recruit the VPS4 ATPases (purple, 1XWI, 1YXR), which completes the membrane fission reaction and uses the energy of ATPase to release the ESCRT-III from the membrane and back into the cytoplasm. See text for details. 
et al. 2011). Humans have 12 different ESCRTIII-like proteins (predominantly known by "CHMP" designations), which can be subdivided into seven families. These proteins share a common architecture, with an amino-terminal core domain comprising an extended fourhelix bundle (Muziol et al. 2006; Bajorek et al. 2009; Xiao et al. 2009), and carboxy-terminal tails that can fold back and autoinhibit core oligomerization (Lin et al. 2005; Zamborlini et al. 2006; Lata et al. 2008a; Bajorek et al. 2009). Only the CHMP2 and CHMP4 families play critical functional roles in HIV-1 budding, although CHMP1 and CHMP3 family members may also contribute modestly (Jouvenet et al. 2011; Morita et al. 2011). The ESCRT-I interactions that lead to CHMP2/CHMP4 recruitment are not yet clear, but the ALIX branch of the pathway is better understood. As illustrated in Figure 5, the following sequence of events is consistent with current analyses of ESCRT pathway recruitment. (1) Late domain binding induces the soluble ALIX protein to undergo a conformation change that leads to dimerization and activates ALIX for membrane binding and ESCRT-III recruitment (Pires et al. 2009; Usami et al. 2009). (2) The Bro domain of the activated ALIX protein binds carboxy-terminal helices located within the tails of all three human CHMP4 proteins (McCullough et al. 2008). (3) This interaction relieves CHMP4 autoinhibition and induces the protein to polymerize into filaments within the virion neck (Hanson et al. 2008; Pires et al. 2009; Usami et al. 2009; Hurley and Hanson 2010; Peel et al. 2011). (4) CHMP4 filaments then recruit (or copolymerize with) the CHMP2 proteins (Lata et al. 2008b; Morita et al. 2011). (5) Deposition of CHMP2 exposes the protein's carboxyterminal tail, which contains a helical sequence motif that binds the amino-terminal MIT domains of VPS4 ATPases (Obita et al. 2007; Stuchell-Brereton et al. 2007; Hurley and Yang 2008). (6) The recruited VPS4 proteins assemble into enzymatically active higher order complexes (Babst et al. 1998; Scott et al. 2005; Shestakova et al. 2010). Like most other AAA ATPases, VPS4 forms hexameric rings, and the active enzyme appears to comprise two stacked, inequivalent hexameric rings (Yu et al. 2008) (although alternative models have been proposed). Each virus budding site recruits approximately three to five VPS4 dodecamers (Baumgartel et al. 2011), which may be linked together through bridges composed of the CHMP5/LIP5 activator complex (Yang and Hurley 2010). The entire ESCRT assembly process takes approximately 10 minutes and occurs in multiple stages, with a gradual and concomitant buildup of the Gag and ALIX proteins, followed by short $(\sim 2 \mathrm{~min})$ bursts of ESCRT-III and VPS4 recruitment immediately prior to virus budding (Baumgartel et al. 2011; Jouvenet et al. 2011).

\section{Models for Membrane Fission}

The detailed mechanism of ESCRT-mediated membrane fission is an active research frontier, but several important aspects of the process have recently emerged. CHMP4 subunits, possibly in complex with CHMP2 and other ESCRT-III proteins, appear to form spiraling filaments within the neck of the budding virus (Fig. 5; Ghazi-Tabatabai et al. 2008; Hanson et al. 2008; Lata et al. 2008b; Teis et al. 2008; Saksena et al. 2009; Wollert et al. 2009; Elia et al. 2011; Guizetti et al. 2011). As the filaments spiral inward, they may create closed "domes" that constrict the opposing membranes and promote fission (Fabrikant et al. 2009; Hurley and Hanson 2010; Peel et al. 2011). VPS4 also apparently plays an active role in the membrane fission reaction because the enzyme is recruited immediately prior to virus budding (Baumgartel et al. 2011; Elia et al. 2011; Jouvenet et al. 2011), and because ESCRT-III recruitment alone is insufficient for virus release (Jouvenet et al. 2011). Possible roles for VPS4 include helping to promote ESCRT-III dome formation and/or removing ESCRT-III subunits from the dome, thereby destabilizing hemi-fission intermediates and helping to drive fission to completion (Hanson et al. 2008; Lata et al. 2008b; Baumgartel et al. 2011; Peel et al. 2011). In the final stage of the cycle, VPS4 uses the energy of ATP hydrolysis to disassemble the filaments and release the ESCRT-III subunits back into the cytoplasm as soluble, autoinhibited 
W.I. Sundquist and H.-G. Kräusslich

proteins (Babst et al. 1998; Ghazi-Tabatabai et al. 2008; Lata et al. 2008b; Wollert et al. 2009; Davies et al. 2010). Thus, the energy required for virus budding is provided by ATP hydrolysis, in the form of VPS4-mediated protein disassembly and refolding.

\section{Blocks to HIV-1 Release}

HIV-1 budding and release are essential for spreading viral infection, and it is therefore not surprising that innate immune pathways have evolved to interfere with these processes. It is now well established that the antiviral protein tetherin blocks HIV-1 dissemination by tethering newly budded viral particles to the cell surface. Tetherin is antagonized by the HIV-1 Vpu protein, and this remarkable restriction system is described in detail in Malim and Bieniasz (2011). Recently, Leis and colleagues have reported that another interferon-inducible protein, ISG-15, can inhibit HIV-1 release at the earlier budding stage by interfering with ESCRT-III protein activities. ISG-15 is a ubiquitin-like protein that can be covalently attached to the lysine side chains of ESCRT-III subunits (Skaug and Chen 2010). ISGylation of CHMP5 and other ESCRT-III subunits appears to impair VPS4 function by sequestering the LIP5-CHMP5 activator away from the enzyme and by reducing VPS4 recruitment and activity (Pincetic et al. 2010; Kuang et al. 2011). It will now be important to determine the relative contributions of these activities in inhibiting HIV-1 replication in vivo and how the virus overcomes such blocks.

\section{HIV MATURATION}

\section{Architecture of the Mature HIV-1 Virion}

Viral maturation begins concomitant with (or immediately following) budding, and is driven by viral PR cleavage of the Gag and Gag-ProPol polyproteins at ten different sites, ultimately producing the fully processed MA, CA, NC, p6, $\mathrm{PR}, \mathrm{RT}$, and IN proteins (Fig. 1A-C; see online Movie 3 at www.perspectivesinmedicine.org; Swanstrom and Wills 1997; Hill et al. 2005). Over the course of maturation, these processed proteins rearrange dramatically to create the mature infectious virion, with its characteristic conical core (Fig. 1D-G). MA remains associated with the inner leaflet of the viral membrane, forming a discontinuous matrix shell that lacks long-range order. The outer capsid shell of the core particle is composed of approximately 1200 copies of CA and is typically conical, although tubes and other aberrant assemblies, including double capsids, also form at lower frequencies (Briggs et al. 2003b; Benjamin et al. 2005). The capsid approaches the matrix closely at both ends (Benjamin et al. 2005; Briggs et al. 2006), particularly at the narrow end, which may represent the nucleation site for assembly (Briggs et al. 2006). The capsid surrounds the nucleocapsid, which typically resides at the wide end of the capsid and lacks obvious long-range order (Briggs et al. 2006).

\section{The Viral Capsid}

The capsid performs essential functions during the early stages of HIV-1 replication, although these functions are not yet fully understood in mechanistic detail. In newly infected cells, the capsid interacts with both positive-acting host factors like cyclophilin A and transportin-3, and with restriction factors of the TRIM5- $\alpha$ family (Luban 2007; Sebastian and Luban 2007; Yamashita and Emerman 2009; Krishnan et al. 2010). CA mutations that block capsid assembly or destabilize the capsid typically inhibit reverse transcription, implying that the capsid helps to organize the replicating genome (Forshey et al. 2002). Conversely, mutations that hyperstabilize the capsid also inhibit reverse transcription, implying that the capsid must disassemble or uncoat in a timely fashion (Forshey et al. 2002). CA mutations can also inhibit or alter nuclear localization, indicating that the capsid (or at least CA subunits) probably play important roles in nuclear targeting and/or import of the preintegration complex (Dismuke and Aiken 2006; Yamashita et al. 2007; Lee et al. 2010).

HIV-1 capsids are geometric structures called "fullerene cones" (Fig. 6A), which are a family of related structures comprising conical 

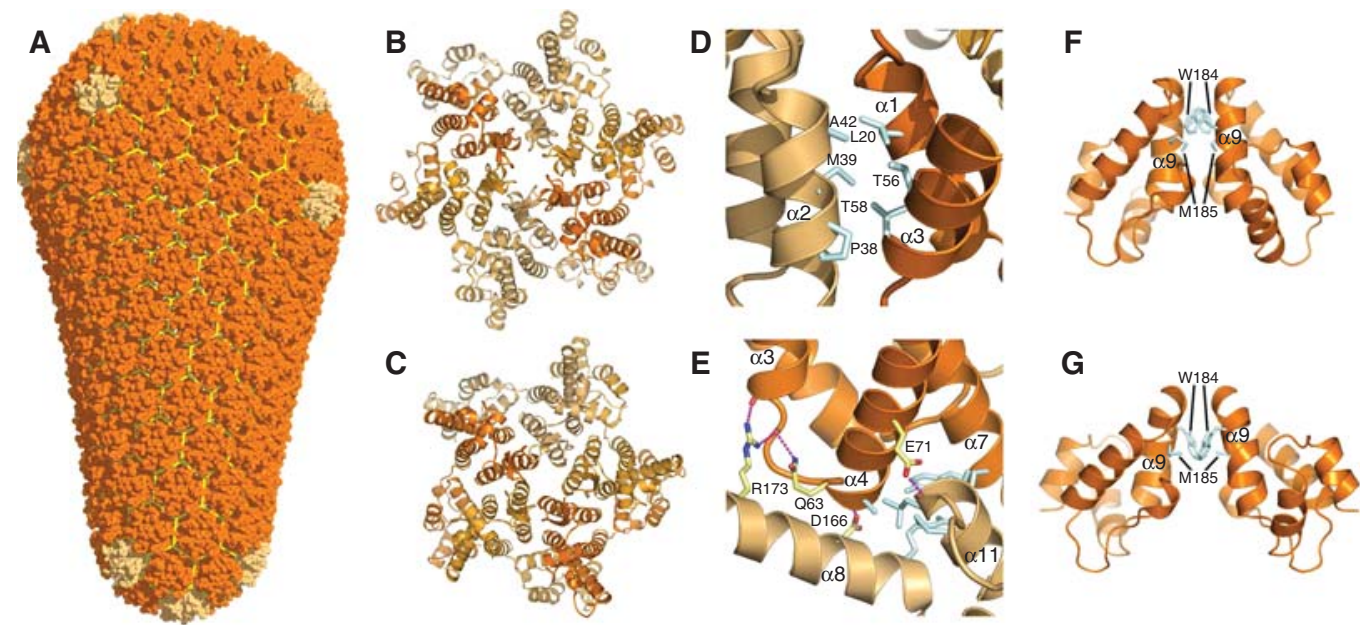

Figure 6. Fullerene cone model for the HIV-1 capsid. (A) Molecular model of the HIV-1 capsid, with CA hexamers in orange and pentamers in tan (adapted from Pornillos et al. 2011). (B) Structure of the HIV-1 CA hexamer (3H47). (C) Structure of the HIV-1 CA pentamer (3P05). (D) Detailed structure of the $\mathrm{CA}_{\mathrm{NTD}}-\mathrm{CA}_{\mathrm{NTD}}$ interface that stabilizes the hexameric ring. Hydrophobic residues that stabilize the interaction between CA helices 1,2 , and 3 are highlighted. (E) Detailed structure of the $\mathrm{CA}_{\mathrm{NTD}}$ (orange) $-\mathrm{CA}_{\mathrm{CTD}}(\tan )$ interface that forms a "girdle" around the hexameric and pentameric rings. Interface residues are highlighted, as are a series of salt bridges and hydrogen bonds that stabilize the interface while allowing it to "swivel" in response to changes in lattice curvature. $(F, G)$ Two alternative structures of the $\mathrm{CA}_{\mathrm{CTD}}$ dimer, $1 \mathrm{~A} 43$ and $2 \mathrm{KOD}$. Two key interface residues (W184 and M185) are shown in each case to emphasize the fact that similar CA surfaces are used in both dimers.

hexagonal nets that close at both ends through the introduction of 12 pentagonal defects (Ganser et al. 1999; Ganser-Pornillos et al. 2008). Thus, unlike icosahedral viruses, HIV-1 capsids are best viewed as a continuum of related structures rather than as a single unique assembly. Most authentic HIV-1 capsids exhibit the $19.2^{\circ}$ cone angle required by conical hexagonal packing, but their overall lengths and cap shapes vary owing to the insertion of pentagons at different positions in the hexagonal net (Benjamin et al. 2005; Briggs et al. 2006). Positioning of pentamers at alternate sites also accounts for the different capsid shapes seen in other retroviruses because "tubular" capsids are created when the 12 pentamers are symmetrically distributed at either end of the tube, and "spherical" capsids are created when the pentamers are distributed more evenly throughout the hexagonal net (Ganser-Pornillos et al. 2004).

A series of different intersubunit CA interactions stabilize the capsid lattice. The CA subunits are organized into hexameric and pentameric rings, and both of these structures have now been visualized crystallographically (Fig. 6B,C; see online Movie 4 at www.per spectivesinmedicine.org; Pornillos et al. 2009, 2011). The organization of subunits within the two types of rings is remarkably similar, and HIV-1 CA hexamers and pentamers are therefore an excellent example of the principle of quasi-equivalence as originally envisioned by Caspar and Klug (1962). In both cases, the rings are stabilized by interactions between the first three helices of $\mathrm{CA}_{\mathrm{NTD}}$ (Fig. 6D). The CA rings are buttressed by an exterior "girdle" formed by $\mathrm{CA}_{\mathrm{CTD}}$, with each $\mathrm{CA}_{\mathrm{CTD}}$ domain contacting the $C A_{\mathrm{NTD}}$ of a neighboring subunit in the ring (Fig. 6B,C,E). CA $\mathrm{A}_{\mathrm{CTD}}$ also makes important inter-ring contacts across the local two- and three-fold axes, thereby stabilizing the extended lattice (Ganser-Pornillos et al. 2007; Byeon et al. 2009). Isolated CA СTD polypeptides can make two different types of twofold symmetric dimers which utilize the same basic interface but differ in their detailed 
packing interactions, and both of these dimers may participate in capsid assembly (Fig. 6F,G; Gamble et al. 1997; Ganser-Pornillos et al. 2007; Byeon et al. 2009).

Fullerene cones lack symmetry, which implies that all of the different CA subunits must reside in distinct local environments. The individual CA subunits must therefore have sufficient flexibility to accommodate at least three different types of heterogeneity. Both CA hexamers and pentamers can be formed because the interface between subunits in the hexameric ring is highly hydrated, and mobile water molecules are well suited for adjusting to the subtle changes required to make the pentamer interface. Alterations in lattice curvature across different regions of the cone surface are accommodated by flexibility in the NTD-CTD linker and in the NTDCTD interface (Fig. 6E), which allows the two CA domains to move relative to one another. Finally, differences in inter-ring packing interactions may be accommodated by using both types of CTD-CTD dimers at different positions of the cone (Pornillos et al. 2011).

\section{The Viral Protease}

HIV-1 PR is one of the most extensively characterized proteins in molecular biology owing to its importance as a drug target (Wlodawer and Gustchina 2000; Louis et al. 2007; Ali et al. 2010; and see Arts and Hazuda 2011). Like other aspartic acid proteases, HIV-1 PR uses two aspartic acid side chains within a characteristic Asp-Thr-Gly “fireman's grip” motif to activate the nucleophilic water molecule that cleaves the peptide bond (Cooper 2002). Retroviral proteases are unusual, however, in that the active enzyme is a dimer of two identical subunits. The active site transverses the dimer interface, stabilized by the fireman's grip and by a four-stranded mixed $\beta$-sheet created by the amino and carboxyl termini of each subunit. Two extended flexible loops lie on the other side of the active site, and these "flaps" open to allow substrates access to the active site (Fig. 1H).

The mechanism by which $\mathrm{PR}$ is activated during Gag assembly and budding is still not fully understood. PR is essentially inactive within the Gag-Pro-Pol polyprotein because the mature active enzyme is a dimer, whereas unprocessed PR constructs with amino-terminal extensions dimerize only very weakly. However, such constructs can form transient dimeric "encounter" complexes. A small fraction of these encounter complexes have enzymatic activity and can accommodate insertion of the amino-terminal cleavage site into the substratebinding cleft, which can lead to autoprocessing and formation of a stable dimer with full catalytic activity (Tang et al. 2008). Gag trafficking probably helps to regulate $\mathrm{PR}$ activation by preventing premature $\mathrm{PR}$ dimerization until the Gag molecules coalesce at the plasma membrane. Consistent with this idea, artificially dimerized PR subunits are activated prematurely, which inhibits particle production (Krausslich et al. 1991). Assembly-mediated PR dimerization is unlikely to account for the entire activation mechanism, however, because Mason-Pfizer monkey virus and other betaretroviruses preassemble into immature particles in the cytoplasm, yet their PR enzymes are not activated until they are transported and bud from the plasma membrane (Parker and Hunter 2001). Thus, PR must be activated by additional mechanisms, at least in the betaretroviruses.

During viral maturation, PR cleaves five different sites within Gag (Fig. 1B) and five different sites within Gag-Pro-Pol (not shown). Schiffer and colleagues have determined crystal structures of HIV-1 PR in complex with peptides that correspond to seven of these cleavage sites (Prabu-Jeyabalan et al. 2002, 2004). Binding of asymmetric substrates breaks the twofold symmetry, so that the two PR subunits are no longer equivalent. Substrates bind in extended, $\beta$-strand conformations and make sheet-like interactions with the flaps and the base of the PR active site. The eight side chains from four residues on either side of the scissile bond bind in a series of six different enzyme pockets (with the first and third residues on either side of the scissile bond sharing common pockets). The enzyme appears to recognize the overall shape of the substrate rather than its specific sequence, as evidenced by the fact that the 
HIV Assembly, Budding, and Maturation

different Gag and Gag-Pro-Pol cleavage sites vary considerably in amino acid sequence, yet all bind within the enzyme with very similar steric footprints (Prabu-Jeyabalan et al. 2002).

\section{Maturation Dynamics}

Important changes that occur during HIV-1 maturation include activation of the fusogenic activity of the viral Env protein (Murakami et al. 2004; Wyma et al. 2004), capsid assembly, stabilization of the genomic RNA dimer, and rearrangement of the $\mathrm{tRNA}^{\mathrm{Lys}, 3}$ primergenome complex (Moore et al. 2009; Rein 2010). Maturation is a dynamic, multistep process that involves a series of conformational switches and subunit rearrangements. Temporal control of viral maturation is provided, at least in part, by the very different rates of processing at the five Gag processing sites, whose cleavage rates vary by up to 400 -fold. These cleavage sites fall into three different categories: rapid (SP1/ $\mathrm{NC}$ ), intermediate (SP2/p6, MA/CA), and slow (NC/SP2, CA/SP1) (Pettit et al. 1994). Analyses of mutant virions with blockages at the different Gag sites indicate that each cleavage event performs a different function. SP1/ NC cleavage activates Env (Wyma et al. 2004) and promotes condensation of the RNP particle (de Marco et al. 2010), SP2 processing frees NC to chaperone formation of the stable genomic RNA dimer (Kafaie et al. 2008; Ohishi et al. 2011), MA/CA cleavage disassembles the immature lattice and releases CA-SP1, and CA-SP1 cleavage frees CA to form the conical capsid (de Marco et al. 2010). In at least some cases, Gag proteolysis induces local conformational changes that favor alternative proteinprotein interactions. For example, cleavage at the MA/CA site causes the first 13 CA residues, which are disordered in the MA-CA protein, to fold into a $\beta$-hairpin that packs above the first three $\mathrm{CA}_{\mathrm{NTD}}$ helices and promotes the formation of mature CA hexamers (Gitti et al. 1996; Tang et al. 2002). Cleavage at the CA-SP1 junction also appears to trigger a conformational rearrangement (Gross et al. 2000), although the molecular details of this transition are not yet well understood.

\section{SITES OF VIRUS RELEASE AND CELL-TO-CELL TRANSMISSION}

\section{HIV-1 Assembles and Buds at the Plasma Membrane}

The general view that HIV-1 assembles and buds at the plasma membrane of the infected cell was challenged by electron microscopy studies reporting budding sites and released virions in apparently intracellular compartments in macrophages and other cell lines. These compartments were reactive for late endosomal markers, which-in combination with the ESCRT requirement for virion release-led to the suggestion that HIV buds into multivesicular bodies and is subsequently released from the cell via vesicular transport and fusion at the plasma membrane (PelchenMatthews et al. 2003). This concept is incompatible with several more recent results, however, showing that newly synthesized Gag reaches the plasma membrane before it accumulates at late endosomes and that endosomal accumulation can be inhibited without effect on virus release (Jouvenet et al. 2006). More importantly, fluorescence microscopy analysis of HIV-1 formation in living cells (Jouvenet et al. 2008; Ivanchenko et al. 2009) only detected single particle assembly at the plasma membrane, inconsistent with vesicular release of preassembled virions from a vesicular compartment. The apparently intracellular sites of HIV-1 assembly and budding in macrophages were ultimately shown to be deep plasma membrane invaginations that were connected to the surface via narrow channels, but were nevertheless accessible to membrane-impermeant stains (Deneka et al. 2007; Welsch et al. 2007) and traceable through ion-abrasion scanning electron microscopy (Bennett et al. 2009). Thus, HIV-1 assembly and budding appears to occur predominantly at the plasma membrane in all physiologically relevant cells.

\section{The Virological Synapse}

Polarized HIV-1 release was initially observed in electron microscopy studies that reported accumulation of HIV-1 budding at sites of 
cell-to-cell contact (Phillips and Bourinbaiar 1992). These observations were consistent with the idea that direct cell-to-cell spread of HIV-1 via specialized cell contacts is much more efficient than infection with cell-free virus and is thus likely to represent the predominant mode of virus spread in vivo, particularly within lymphoid tissues. Microscopic studies of $\mathrm{CD} 4^{+}$ T-cell cultures later revealed close connections between infected donor cells and uninfected target cells, and cell-to-cell transmission of virions across these contact zones, which were termed virological synapses (VS) (Piguet and Sattentau 2004; Mothes et al. 2010; Jolly and Sattentau 2004; Haller and Fackler 2008). This name was chosen because the structures were reminiscent of immunological synapses, even though the two structures are clearly distinct in terms of protein composition, signaling, and dynamics (Vasiliver-Shamis et al. 2010). Multiple contact zones between one HIVinfected $\mathrm{CD}^{+}{ }^{+} \mathrm{T}$ cell and several uninfected cells were also observed and have been termed polysynapses (Rudnicka 2009). VS have been described between infected and uninfected $\mathrm{CD}^{+} \mathrm{T}$ cells, between macrophages and $\mathrm{CD}^{+}{ }^{+} \mathrm{T}$ cells, and between virus-exposed dendritic cells and $\mathrm{CD} 4^{+} \mathrm{T}$ cells. Although all of these contact zones are likely to serve analogous functions in enhancing virus transmission, there are some fundamental differences: In VS between $\mathrm{T}$ cells, polarized HIV-1 release and subsequent target cell entry occurs across the VS (Piguet and Sattentau 2004), whereas in macrophages virions that have accumulated within the invaginated compartment (see above) are brought toward the contact zone (Gousset et al. 2008). Mature DCs capture cellfree virions into a compartment that stains for late endosomal markers, with subsequent transport and release toward the cell contact zone. The ultrastructure of this contact zone has been analyzed by ion abrasion scanning electron microscopy and electron tomography, which show a close envelopment of the $\mathrm{T}$ cells into DC-derived sheet-like membrane extensions, sometimes containing T-cell filopodia. This close interaction provides a shielded environment that allows CD4-dependent transfer of sequestered virions from DCs to the T-cell surface and subsequent infection (Felts et al. 2010).

Viral and cellular components that polarize on the producer cell of the T-cell VS include HIV-1 Gag and Env, cellular tetraspanins, and the microtubule organizing center (MTOC), whereas HIV-1 receptors (CD4 and coreceptors) and the actin cytoskeleton polarize on the target cell (Haller and Fackler 2008). VS formation is dependent on HIV-1 Env proteins on the producer cell and viral receptors on the target cell, and is therefore a virus-induced structure. The contact zone in the producer cell is enriched in "raft" marker proteins and the VS is destroyed by cholesterol depletion, suggesting that membrane microdomains also make important contributions. Polarization and VS formation are dependent on an intact microtubule and actin cytoskeleton, and the VS can be stabilized by interactions of the cellular adhesion molecules ICAM-1 and LFA-1 (Jolly et al. 2007). ZAP-70, a kinase that regulates T-cell signaling and immunological synapse formation, is also required for polarized localization of HIV structural proteins, VS formation, and efficient cell-to-cell spread (Sol-Foulon et al. 2007).

The intracellular tail of the TM protein appears to be essential for polarized targeting of Env and Gag as well as for efficient spread of both murine leukemia virus (Jin et al. 2009) and HIV-1 (Emerson et al. 2010). HIV-1 Gag localizes to the trailing end of polarized T cells, termed the uropod, and this localization appears to depend on the formation of higher order oligomers and requires the NC domain (Llewellyn et al. 2010).

Despite their different names, infections that occur via cell-to-cell transfer and via cellfree particles both involve production of cellfree virions and likely involve fundamentally similar molecular mechanisms of virus assembly, budding, and release. Electron microscopy and tomographic (Martin et al. 2010) studies of VS revealed HIV budding events and numerous virions within the T-cell VS, which appeared to be loosely structured and to have few points of immediate contact, suggesting that the structure is relatively permeable. Transfer of viral material through the VS was 
HIV Assembly, Budding, and Maturation

observed by video microscopy (Hubner et al. 2009) and reportedly involved micrometersized Gag-positive structures, which are far larger than individual virions, whereas parallel EM images showed individual HIV-1 budding sites within in the contact zone. It is unclear, therefore, whether the observed transfer events corresponded to HIV-1 infections or to transfer of vesicular material destined for lysosomal destruction. A cautious interpretation of these observations is also warranted because only a low number of actual infections were observed despite the presence of numerous budding sites and virions in the contact zone.

In principle, the VS could enhance HIV-1 transmission in several different ways. Virion release within a relatively closed environment and in the immediate vicinity of a target cell surface enriched in entry receptors provides one obvious advantage over cell-free infections, which are limited by extracellular diffusion and random cell surface attachment. Cell-tocell contacts between uninfected and infected cells may also induce signaling pathways and activate the target cell, thus making it more permissive for HIV-1 infection. Finally, several studies have suggested that the VS could shield newly produced virions from circulating neutralizing antibodies and entry inhibitors (Chen et al. 2007; Hubner et al. 2009). However, those reports have not been confirmed in more recent studies (Massanella et al. 2009; Martin et al. 2010) and also seem inconsistent with ultrastructural analyses that suggest a relatively loose contact zone. Thus, the VS appears not to confer protection from neutralization or chemotherapeutic agents.

\section{Membrane Bridges and Cell-to-Cell Transmission}

Besides VS, several types of membrane bridges have been reported to enhance cell-to-cell transmission of HIV-1 and other retroviruses (Sherer and Mothes 2008; Mothes et al. 2010). Such structures include filopodial bridges, termed cytonemes, which have been shown to support the spread of murine leukemia virus (Sherer 2007), and membrane nanotubes, which can link
$\mathrm{CD}^{+}{ }^{+} \mathrm{T}$ cells and support HIV transfer (Sherer and Mothes 2008; Sowinski et al. 2008). Importantly, virion transport again occurs on the outer surfaces of these membrane connections, and therefore apparently involves normal budding and receptor-mediated entry processes. Although these structures are certainly intriguing, their relative contributions to retrovirus spread in vivo are difficult to quantify.

\section{PERSPECTIVES}

Despite considerable progress, a number of key aspects of HIV-1 assembly, budding, and maturation are not yet well understood and represent important research frontiers. The most pressing issues that need to be addressed include (1) determining the structure of the immature Gag lattice at high resolution, (2) defining the precise mechanism of membrane fission during virus budding, (3) elucidating the mechanism of PR activation, (4) defining the different stages of viral maturation in molecular detail, and (5) characterizing viral capsid functions and the mechanism of capsid uncoating during the early stages of the viral life cycle. Significant progress has already been made in identifying small molecule inhibitors of capsid assembly, budding, and maturation (Adamson et al. 2009; Blair et al. 2009; Jiang et al. 2011), and these efforts will undoubtedly be aided by a greater understanding of the molecular virology, biochemistry, and structural biology of these important viral processes.

\section{ACKNOWLEDGMENTS}

We thank John Briggs, Grant Jensen, John McCullough, Owen Pornillos, Jack Skalicky, and Mike Summers for help with figures and Barbara Müller and Oliver Fackler for suggestions and critical reading of the manuscript. HIV research in the Sundquist lab is supported by NIH grants R37 AI045405, R01 AI051174, and P50 GM082545; the Kräusslich lab is supported by grants from the Deutsche Forschungsgemeinschaft (SFB544 B11, SFB638, A9, SPP1175). 
W.I. Sundquist and H.-G. Kräusslich

\section{REFERENCES}

* Reference is also in this collection.

Accola MA, Hoglund S, Gottlinger HG. 1998. A putative alpha-helical structure which overlaps the capsid-p2 boundary in the human immunodeficiency virus type 1 Gag precursor is crucial for viral particle assembly. J Virol 72: $2072-2078$.

Accola MA, Strack B, Gottlinger HG. 2000. Efficient particle production by minimal Gag constructs which retain the carboxy-terminal domain of human immunodeficiency virus type 1 capsid-p2 and a late assembly domain. J Virol 74: 5395-5402.

Adamson CS, Salzwedel K, Freed EO. 2009. Virus maturation as a new HIV-1 therapeutic target. Expert Opin Ther Targets 13: 895-908.

Ali A, Reddy GS, Nalam MN, Anjum SG, Cao H, Schiffer CA, Rana TM. 2010. Structure-based design, synthesis, and structure-activity relationship studies of HIV-1 protease inhibitors incorporating phenyloxazolidinones. $J$ Med Chem 53: 7699-7708.

Aloia RC, Jensen FC, Curtain CC, Mobley PW, Gordon LM 1988. Lipid composition and fluidity of the human immunodeficiency virus. Proc Natl Acad Sci 85: 900-904.

Aloia RC, Tian H, Jensen FC. 1993. Lipid composition and fluidity of the human immunodeficiency virus envelope and host cell plasma membranes. Proc Natl Acad Sci 90: 5181-5185.

Andrawiss M, Takeuchi Y, Hewlett L, Collins M. 2003. Murine leukemia virus particle assembly quantitated by fluorescence microscopy: role of Gag-Gag interactions and membrane association. J Virol 77: 11651-11660.

* Arts EJ, Hazuda DJ. 2011. HIV-1 antiretroviral drug therapy. Cold Spring Harb Perspect Med doi: 10.1101/ cshperspect.a007161.

Babst M, Wendland B, Estepa EJ, Emr SD. 1998. The Vps4p AAA ATPase regulates membrane association of a Vps protein complex required for normal endosome function. EMBO J 17: 2982-2993.

Bajorek M, Schubert HL, McCullough J, Langelier C, Eckert DM, Stubblefield WM, Uter NT, Myszka DG, Hill CP, Sundquist WI. 2009. Structural basis for ESCRT-III protein autoinhibition. Nat Struct Mol Biol 16: 754-762.

Bartonova V, Igonet S, Sticht J, Glass B, Habermann A, Vaney MC, Sehr P, Lewis J, Rey FA, Krausslich HG. 2008. Residues in the HIV-1 capsid assembly inhibitor binding site are essential for maintaining the assemblycompetent quaternary structure of the capsid protein. $J$ Biol Chem 283: 32024-32033.

Batonick M, Favre M, Boge M, Spearman P, Honing S, Thali M. 2005. Interaction of HIV-1 Gag with the clathrinassociated adaptor AP-2. Virology 342: 190-200.

Baumgartel V, Ivanchenko S, Dupont A, Sergeev M, Wiseman PW, Krausslich HG, Brauchle C, Muller B, Lamb DC. 2011. Live-cell visualization of dynamics of HIV budding site interactions with an ESCRT component. Nat Cell Biol 13: 469-474.

Benjamin J, Ganser-Pornillos BK, Tivol WF, Sundquist WI Jensen GJ. 2005. Three-dimensional structure of HIV-1 virus-like particles by electron cryotomography. $\mathrm{J} \mathrm{Mol}$ Biol 346: 577-588.
Bennett AE, Narayan K, Shi D, Hartnell LM, Gousset K, He H, Lowekamp BC, Yoo TS, Bliss D, Freed EO, et al. 2009. Ion-abrasion scanning electron microscopy reveals surface-connected tubular conduits in HIV-infected macrophages. PLoS Pathog 5: e1000591.

Bieniasz PD. 2009. The cell biology of HIV-1 virion genesis. Cell Host Microbe 5: 550-558.

Blair WS, Cao J, Fok-Seang J, Griffin P, Isaacson J, Jackson RL, Murray E, Patick AK, Peng Q, Perros M, et al. 2009. New small-molecule inhibitor class targeting human immunodeficiency virus type 1 virion maturation. Antimicrob Agents Chemother 53: 5080-5087.

Briggs JA, Wilk T, Fuller SD. 2003a. Do lipid rafts mediate virus assembly and pseudotyping? J Gen Virol 84: $757-$ 768.

Briggs JA, Wilk T, Welker R, Krausslich HG, Fuller SD. 2003b. Structural organization of authentic, mature HIV-1 virions and cores. EMBO J 22: 1707-1715.

Briggs JA, Grunewald K, Glass B, Forster F, Krausslich HG, Fuller SD. 2006. The mechanism of HIV-1 core assembly: Insights from three-dimensional reconstructions of authentic virions. Structure 14: 15-20.

Briggs JA, Riches JD, Glass B, Bartonova V, Zanetti G, Krausslich HG. 2009. Structure and assembly of immature HIV. Proc Natl Acad Sci 106: 11090-11095.

Brugger B, Glass B, Haberkant P, Leibrecht I, Wieland FT, Krausslich HG. 2006. The HIV lipidome: A raft with an unusual composition. Proc Natl Acad Sci 103: 26412646.

Byeon IJ, Meng X, Jung J, Zhao G, Yang R, Ahn J, Shi J, Concel J, Aiken C, Zhang P, et al. 2009. Structural convergence between Cryo-EM and NMR reveals intersubunit interactions critical for HIV-1 capsid function. Cell 139: $780-790$.

Camus G, Segura-Morales C, Molle D, Lopez-Verges S, Begon-Pescia C, Cazevieille C, Schu P, Bertrand E, Berlioz-Torrent C, Basyuk E. 2007. The clathrin adaptor complex AP-1 binds HIV-1 and MLV Gag and facilitates their budding. Mol Biol Cell 18: 3193-3203.

Carlson LA, Briggs JA, Glass B, Riches JD, Simon MN, Johnson MC, Muller B, Grunewald K, Krausslich HG. 2008. Three-dimensional analysis of budding sites and released virus suggests a revised model for HIV-1 morphogenesis. Cell Host Microbe 4: 592-599.

Carlson LA, de Marco A, Oberwinkler H, Habermann A, Briggs JA, Krausslich HG, Grunewald K. 2010. Cryo electron tomography of native HIV-1 budding sites. PLoS Pathog 6: e1001173.

Carlton JG, Martin-Serrano J. 2007. Parallels between cytokinesis and retroviral budding: A role for the ESCRT machinery. Science 316: 1908-1912.

Carlton JG, Martin-Serrano J. 2009. The ESCRT machinery: New functions in viral and cellular biology. Biochem Soc Trans 37: 195-199.

Caspar DL, Klug A. 1962. Physical principles in the construction of regular viruses. Cold Spring Harb Symp Quant Biol 27: 1-24.

Chan R, Uchil PD, Jin J, Shui G, Ott DE, Mothes W, Wenk MR. 2008. Retroviruses human immunodeficiency virus and murine leukemia virus are enriched in phosphoinositides. J Virol 82: 11228-11238. 
HIV Assembly, Budding, and Maturation

Chen P, Hubner W, Spinelli MA, Chen BK. 2007. Predominant mode of human immunodeficiency virus transfer between $\mathrm{T}$ cells is mediated by sustained Env-dependent neutralization-resistant virological synapses. J Virol 81: $12582-12595$.

Chen J, Nikolaitchik O, Singh J, Wright A, Bencsics CE, Coffin JM, Ni N, Lockett S, Pathak VK, Hu WS. 2009. High efficiency of HIV-1 genomic RNA packaging and heterozygote formation revealed by single virion analysis. Proc Natl Acad Sci 106: 13535-13540.

Chertova E, Bess JW Jr, Crise BJ, Sowder IR, Schaden TM, Hilburn JM, Hoxie JA, Benveniste RE, Lifson JD, Henderson LE, et al. 2002. Envelope glycoprotein incorporation, not shedding of surface envelope glycoprotein (gp120/ $\mathrm{SU}$ ), is the primary determinant of SU content of purified human immunodeficiency virus type 1 and simian immunodeficiency virus. J Virol 76: 5315-5325.

Chukkapalli V, Oh SJ, Ono A. 2010. Opposing mechanisms involving RNA and lipids regulate HIV-1 Gag membrane binding through the highly basic region of the matrix domain. Proc Natl Acad Sci 107: 1600-1605.

Chung HY, Morita E, von Schwedler U, Muller B, Krausslich HG, Sundquist WI. 2008. NEDD4L overexpression rescues the release and infectivity of human immunodeficiency virus type 1 constructs lacking PTAP and YPXL late domains. J Virol 82: 4884-4897.

Cooper JB. 2002. Aspartic proteinases in disease: A structural perspective. Curr Drug Targets 3: 155-173.

Cosson P. 1996. Direct interaction between the envelope and matrix proteins of HIV-1. EMBO J 15: 5783-5788.

D'Souza V, Summers MF. 2005. How retroviruses select their genomes. Nat Rev 3: 643-655.

Datta SA, Heinrich F, Raghunandan S, Krueger S, Curtis JE, Rein A, Nanda H. 2011a. HIV-1 Gag extension: Conformational changes require simultaneous interaction with membrane and nucleic acid. J Mol Biol 406: 205-214.

Datta SA, Temeselew LG, Crist RM, Soheilian F, Kamata A, Mirro J, Harvin D, Nagashima K, Cachau RE, Rein A. 2011b. On the role of the SP1 domain in HIV-1 particle assembly: A molecular switch? J Virol 85: 4111-4121.

Davies BA, Azmi IF, Payne J, Shestakova A, Horazdovsky BF, Babst M, Katzmann DJ. 2010. Coordination of substrate binding and ATP hydrolysis in Vps4-mediated ESCRT-III disassembly. Mol Biol Cell 21: 3396-3408.

de Marco A, Muller B, Glass B, Riches JD, Krausslich HG, Briggs JA. 2010. Structural analysis of HIV-1 maturation using cryo-electron tomography. PLoS Pathog 6: e1001215.

Demirov DG, Ono A, Orenstein JM, Freed EO. 2002. Overexpression of the N-terminal domain of TSG101 inhibits HIV-1 budding by blocking late domain function. Proc Natl Acad Sci 99: 955-960.

Deneka M, Pelchen-Matthews A, Byland R, Ruiz-Mateos E, Marsh M. 2007. In macrophages, HIV-1 assembles into an intracellular plasma membrane domain containing the tetraspanins CD81, CD9, and CD53. J Cell Biol 177: 329-341.

Dismuke DJ, Aiken C. 2006. Evidence for a functional link between uncoating of the human immunodeficiency virus type 1 core and nuclear import of the viral preintegration complex. J Virol 80: 3712-3720.
Dong X, Li H, Derdowski A, Ding L, Burnett A, Chen X, Peters TR, Dermody TS, Woodruff E, Wang JJ, et al. 2005. AP-3 directs the intracellular trafficking of HIV-1 Gag and plays a key role in particle assembly. Cell 120: 663-674.

Dooher JE, Schneider BL, Reed JC, Lingappa JR. 2007. Host ABCE1 is at plasma membrane HIV assembly sites and its dissociation from Gag is linked to subsequent events of virus production. Traffic 8: 195-211.

Dupont S, Sharova N, DeHoratius C, Virbasius CM, Zhu X, Bukrinskaya AG, Stevenson M, Green MR. 1999. A novel nuclear export activity in HIV-1 matrix protein required for viral replication. Nature 402: 681-685.

Dussupt V, Javid MP, Abou-Jaoude G, Jadwin JA, de La Cruz J, Nagashima K, Bouamr F. 2009. The nucleocapsid region of HIV-1 Gag cooperates with the PTAP and LYPXnL late domains to recruit the cellular machinery necessary for viral budding. PLoS Pathog 5: e1000339.

Eekels JJ, Geerts D, Jeeninga RE, Berkhout B. 2011. Longterm inhibition of HIV-1 replication with RNA interference against cellular co-factors. Antivir Res 89: 43-53.

Einfeld D. 1996. Maturation and assembly of retroviral glycoproteins. Curr Top Microbiol Immunol 214: 133-176.

Elia N, Sougrat R, Spurlin TA, Hurley JH, LippincottSchwartz J. 2011. Dynamics of endosomal sorting complex required for transport (ESCRT) machinery during cytokinesis and its role in abscission. Proc Natl Acad Sci 108: $4846-4851$.

Emerson V, Haller C, Pfeiffer T, Fackler OT, Bosch V. 2010. Role of the C-terminal domain of the HIV-1 glycoprotein in cell-to-cell viral transmission between T-lymphocytes. Retrovirology 7: 43.

Fabrikant G, Lata S, Riches JD, Briggs JA, Weissenhorn W, Kozlov MM. 2009. Computational model of membrane fission catalyzed by ESCRT-III. PLoS Comput Biol 5: e1000575.

Felts RL, Narayan K, Estes JD, Shi D, Trubey CM, Fu J, Hartnell LM, Ruthel GT, Schneider DK, Nagashima K, et al. 2010. 3D visualization of HIV transfer at the virological synapse between dendritic cells and T cells. Proc Natl Acad Sci 107: 13336-13341.

Forshey BM, von Schwedler U, Sundquist WI, Aiken C. 2002. Formation of a human immunodeficiency virus type 1 core of optimal stability is crucial for viral replication. J Virol 76: 5667-5677.

Frankel AD, Young JA. 1998. HIV-1: Fifteen proteins and an RNA. Annu Rev Biochem 67: 1-25.

Freed EO. 2001. HIV-1 replication. Somat Cell Molec Gen 26: $13-33$.

Fujii K, Munshi UM, Ablan SD, Demirov DG, Soheilian F, Nagashima K, Stephen AG, Fisher RJ, Freed EO. 2009. Functional role of Alix in HIV-1 replication. Virology 391: $284-292$.

Fuller SD, Wilk T, Gowen BE, Krausslich HG, Vogt VM. 1997. Cryo-electron microscopy reveals ordered domains in the immature HIV-1 particle. Curr Biol 7: 729-738.

Gamble TR, Yoo S, Vajdos FF, von Schwedler UK, Worthylake DK, Wang H, McCutcheon JP, Sundquist WI, Hill CP. 1997. Structure of the carboxyl-terminal dimerization domain of the HIV-1 capsid protein. Science 278: 849-853. 
W.I. Sundquist and H.-G. Kräusslich

Ganser BK, Li S, Klishko VY, Finch JT, Sundquist WI. 1999. Assembly and analysis of conical models for the HIV-1 core. Science 283: 80-83.

Ganser-Pornillos BK, von Schwedler UK, Stray KM, Aiken C, Sundquist WI. 2004. Assembly properties of the human immunodeficiency virus type $1 \mathrm{CA}$ protein. $J$ Virol 78: 2545-2552.

Ganser-Pornillos BK, Cheng A, Yeager M. 2007. Structure of full-length HIV-1 CA: A model for the mature capsid lattice. Cell 131: 70-79.

Ganser-Pornillos BK, Yeager M, Sundquist WI. 2008. The structural biology of HIV assembly. Curr Opin Struct Biol 18: 203-217.

Garrus JE, von Schwedler UK, Pornillos OW, Morham SG, Zavitz KH, Wang HE, Wettstein DA, Stray KM, Cote M, Rich RL, et al. 2001. Tsg101 and the vacuolar protein sorting pathway are essential for HIV-1 budding. Cell 107: $55-65$.

Ghazi-Tabatabai S, Saksena S, Short JM, Pobbati AV, Veprintsev DB, Crowther RA, Emr SD, Egelman EH, Williams RL. 2008. Structure and disassembly of filaments formed by the ESCRT-III subunit Vps24. Structure 16: 1345-1356.

Gitti RK, Lee BM, Walker J, Summers MF, Yoo S, Sundquist WI. 1996. Structure of the amino-terminal core domain of the HIV-1 capsid protein. Science 273: 231-235.

Gousset K, Ablan SD, Coren LV, Ono A, Soheilian F, Nagashima K, Ott DE, Freed EO. 2008. Real-time visualization of HIV-1 GAG trafficking in infected macrophages. PLoS Pathog 4: e1000015.

Gross I, Hohenberg H, Wilk T, Wiegers K, Grattinger M, Muller B, Fuller S, Krausslich HG. 2000. A conformational switch controlling HIV-1 morphogenesis. EMBO J 19: 103-113.

Guizetti J, Schermelleh L, Mantler J, Maar S, Poser I, Leonhardt H, Muller-Reichert T, Gerlich DW. 2011. Cortical constriction during abscission involves helices of ESCRT-III-dependent filaments. Science 331: 16161620.

Haller C, Fackler OT. 2008. HIV-1 at the immunological and T-lymphocytic virological synapse. Biol Chem 389: 1253-1260.

Hamard-Peron E, Juillard F, Saad JS, Roy C, Roingeard P, Summers MF, Darlix JL, Picart C, Muriaux D. 2010. Targeting of murine leukemia virus gag to the plasma membrane is mediated by $\mathrm{PI}(4,5) \mathrm{P} 2 / \mathrm{PS}$ and a polybasic region in the matrix. J Virol 84: 503-515.

Hanson PI, Roth R, Lin Y, Heuser JE. 2008. Plasma membrane deformation by circular arrays of ESCRT-III protein filaments. J Cell Biol 180: 389-402.

Hill M, Tachedjian G, Mak J. 2005. The packaging and maturation of the HIV-1 Pol proteins. Curr HIV Res 3: 73-85.

Hubner W, McNerney GP, Chen P, Dale BM, Gordon RE, Chuang FY, Li XD, Asmuth DM, Huser T, Chen BK. 2009. Quantitative 3D video microscopy of HIV transfer across T cell virological synapses. Science 323: 17431747.

Hurley JH, Hanson PI. 2010. Membrane budding and scission by the ESCRT machinery: It's all in the neck. Nat Rev Mol Cell Biol 11: 556-566.

Hurley JH, Yang D. 2008. MIT domainia. Dev Cell 14: 6-8.
Im YJ, Kuo L, Ren X, Burgos PV, Zhao XZ, Liu F, Burke TR Jr, Bonifacino JS, Freed EO, Hurley JH. 2010. Crystallographic and functional analysis of the ESCRT-I/HIV-1 Gag PTAP interaction. Structure 18: 1536-1547.

Inlora J, Chukkapalli V, Derse D, Ono A. 2011. Gag localization and virus-like particle release mediated by the matrix domain of human T-lymphotropic virus type 1 Gag are less dependent on phosphatidylinositol- $(4,5)$ bisphosphate than those mediated by the matrix domain of HIV-1 Gag. J Virol 85: 3802-3810.

Ivanchenko S, Godinez WJ, Lampe M, Krausslich HG, Eils R, Rohr K, Brauchle C, Muller B, Lamb DC. 2009. Dynamics of HIV-1 assembly and release. PLoS Pathog 5: e1000652.

Ivanov D, Tsodikov OV, Kasanov J, Ellenberger T, Wagner G, Collins T. 2007. Domain-swapped dimerization of the HIV-1 capsid C-terminal domain. Proc Natl Acad Sci 104: $4353-4358$.

Jacks T, Power MD, Masiarz FR, Luciw PA, Barr PJ, Varmus HE. 1988. Characterization of ribosomal frameshifting in HIV-1 gag-pol expression. Nature 331: 280-283.

Jiang Y, Liu X, De Clercq E. 2011.New therapeutic approaches targeted at the late stages of the HIV-1 replication cycle. Curr Med Chem 18: 16-28.

Jin J, Sherer NM, Heidecker G, Derse D, Mothes W. 2009. Assembly of the murine leukemia virus is directed towards sites of cell-cell contact. PLoS Biol 7: e1000163.

Johnson SF, Telesnitsky A. 2010. Retroviral RNA dimerization and packaging: The what, how, when, where, and why. PLoS Pathog 6.

Jolly C, Sattentau QJ. 2004. Retroviral spread by induction of virological synapses. Traffic 5: 643-650.

Jolly C, Mitar I, Sattentau QJ. 2007. Adhesion molecule interactions facilitate human immunodeficiency virus type 1-induced virological synapse formation between T cells. J Virol 81: 13916-13921.

Jones CP, Datta SA, Rein A, Rouzina I, Musier-Forsyth K. 2011. Matrix domain modulates HIV-1 Gag's nucleic acid chaperone activity via inositol phosphate binding. $J$ Virol 85: 1594-1603.

Jouvenet N, Neil SJ, Bess C, Johnson MC, Virgen CA, Simon SM, Bieniasz PD. 2006. Plasma membrane is the site of productive HIV-1 particle assembly. PLoS Biol 4: e435.

Jouvenet N, Bieniasz PD, Simon SM. 2008. Imaging the biogenesis of individual HIV-1 virions in live cells. Nature 454: $236-240$

Jouvenet N, Simon SM, Bieniasz PD. 2009. Imaging the interaction of HIV-1 genomes and Gag during assembly of individual viral particles. Proc Natl Acad Sci 106: 19114-19119.

Jouvenet N, Zhadina M, Bieniasz PD, Simon SM. 2011. Dynamics of ESCRT protein recruitment during retroviral assembly. Nat Cell Biol 13: 394-401.

Kafaie J, Song R, Abrahamyan L, Mouland AJ, Laughrea M. 2008. Mapping of nucleocapsid residues important for HIV-1 genomic RNA dimerization and packaging. Virology 375: 592-610.

Kleiman L, Jones CP, Musier-Forsyth K. 2010. Formation of the tRNALys packaging complex in HIV-1. FEBS Lett 584: $359-365$ 
HIV Assembly, Budding, and Maturation

Kondo E, Mammano F, Cohen EA, Gottlinger HG. 1995. The p6gag domain of human immunodeficiency virus type 1 is sufficient for the incorporation of Vpr into heterologous viral particles. J Virol 69: 2759-2764.

Krausslich HG, Traenckner AM, Rippmann F. 1991. Expression and characterization of genetically linked homoand hetero-dimers of HIV proteinase. Adv Exp Med Biol 306: 417-428.

Krishnan L, Matreyek KA, Oztop I, Lee K, Tipper CH, Li X, Dar MJ, Kewalramani VN, Engelman A. 2010. The requirement for cellular transportin 3 (TNPO3 or TRN-SR2) during infection maps to human immunodeficiency virus type 1 capsid and not integrase. J Virol 84: 397-406.

Kuang Z, Seo EJ, Leis J. 2011. The mechanism of inhibition of retrovirus release from cells by interferon induced gene ISG15. J Virol 85: 7153-7161.

Kutluay SB, Bieniasz PD. 2010. Analysis of the initiating events in HIV-1 particle assembly and genome packaging. PLoS Pathog 6: e1001200.

Lata S, Roessle M, Solomons J, Jamin M, Gottlinger HG, Svergun DI, Weissenhorn W. 2008a. Structural basis for autoinhibition of ESCRT-III CHMP3. J Mol Biol 378: 816-825.

Lata S, Schoehn G, Jain A, Pires R, Piehler J, Gottlinger HG, Weissenhorn W. 2008b. Helical structures of ESCRT-III are disassembled by VPS4. Science 321: 1354-1357.

Lee K, Ambrose Z, Martin TD, Oztop I, Mulky A, Julias JG, Vandegraaff N, Baumann JG, Wang R, Yuen W, et al. 2010. Flexible use of nuclear import pathways by HIV-1. Cell Host Microbe 7: 221-233.

Leung K, Kim JO, Ganesh L, Kabat J, Schwartz O, Nabel GJ. 2008. HIV-1 assembly: Viral glycoproteins segregate quantally to lipid rafts that associate individually with HIV-1 capsids and virions. Cell Host Microbe 3: 285-292.

Lever AM. 2007. HIV-1 RNA packaging. Adv Pharmacol 55: $1-32$.

Lin Y, Kimpler LA, Naismith TV, Lauer JM, Hanson PI. 2005. Interaction of the mammalian endosomal sorting complex required for transport (ESCRT) III protein hSnf7-1 with itself, membranes, and the AAA + ATPase SKD1. J Biol Chem 280: 12799-12809.

Llewellyn GN, Hogue IB, Grover JR, Ono A. 2010. Nucleocapsid promotes localization of HIV-1 gag to uropods that participate in virological synapses between $\mathrm{T}$ cells. PLoS Pathog 6: e1001167.

Lorizate M, Brugger B, Akiyama H, Glass B, Muller B, Anderluh G, Wieland FT, Krausslich HG. 2009. Probing HIV-1 membrane liquid order by Laurdan staining reveals producer cell-dependent differences. J Biol Chem 284: $22238-22247$.

Louis JM, Ishima R, Torchia DA, Weber IT. 2007. HIV-1 protease: Structure, dynamics, and inhibition. Adv Pharmacol 55: $261-298$

Luban J. 2007. Cyclophilin A, TRIM5, and resistance to human immunodeficiency virus type 1 infection. J Virol 81: 1054-1061.

* Malim MH, Bieniasz PD. 2011. HIV restriction factors and mechanisms of evasion. Cold Spring Harb Perspect Med doi: 10.1101/cshperspect.a006940.
Martin N, Welsch S, Jolly C, Briggs JA, Vaux D, Sattentau QJ. 2010. Virological synapse-mediated spread of human immunodeficiency virus type 1 between $T$ cells is sensitive to entry inhibition. J Virol 84: 3516-3527.

Martinez NW, Xue X, Berro RG, Kreitzer G, Resh MD. 2008. Kinesin KIF4 regulates intracellular trafficking and stability of the human immunodeficiency virus type $1 \mathrm{Gag}$ polyprotein. J Virol 82: 9937-9950.

Martin-Serrano J, Zang T, Bieniasz PD. 2001. HIV-1 and Ebola virus encode small peptide motifs that recruit Tsg101 to sites of particle assembly to facilitate egress. Nat Med 7: 1313-1319.

Massanella M, Puigdomenech I, Cabrera C, FernandezFigueras MT, Aucher A, Gaibelet G, Hudrisier D, Garcia E, Bofill M, Clotet B, et al. 2009. Antigp41 antibodies fail to block early events of virological synapses but inhibit HIV spread between T cells. AIDS 23: 183-188.

McCullough J, Fisher RD, Whitby FG, Sundquist WI, Hill CP. 2008. ALIX-CHMP4 interactions in the human ESCRT pathway. Proc Natl Acad Sci 105: 7687-7691.

Miyazaki Y, Garcia EL, King SR, Iyalla K, Loeliger K, Starck P, Syed S, Telesnitsky A, Summers MF. 2010. An RNA structural switch regulates diploid genome packaging by Moloney murine leukemia virus. J Mol Biol 396: $141-152$.

Moore MD, Hu WS. 2009. HIV-1 RNA dimerization: It takes two to tango. AIDS Rev 11: 91-102.

Moore MD, Nikolaitchik OA, Chen J, Hammarskjold ML, Rekosh D, Hu WS. 2009. Probing the HIV-1 genomic RNA trafficking pathway and dimerization by genetic recombination and single virion analyses. PLoS Pathog 5: e1000627.

Morellet N, Druillennec S, Lenoir C, Bouaziz S, Roques BP. 2005. Helical structure determined by NMR of the HIV-1 (345-392)Gag sequence, surrounding p2: Implications for particle assembly and RNA packaging. Protein Sci 14: $375-386$.

Morita E, Sundquist WI. 2004. Retrovirus budding. Annu Rev Cell Dev Biol 20: 395-425.

Morita E, Sandrin V, McCullough J, Katsuyama A, Baci Hamilton I, Sundquist WI. 2011. ESCRT-III protein requirements for HIV-1 budding. Cell Host Microbe 9: 235-242.

Mortuza GB, Haire LF, Stevens A, Smerdon SJ, Stoye JP, Taylor IA. 2004. High-resolution structure of a retroviral capsid hexameric amino-terminal domain. Nature 431: 481-485.

Mothes W, Sherer NM, Jin J, Zhong P. 2010. Virus cell-to-cell transmission. J Virol 84: 8360-8368.

Muller B, Tessmer U, Schubert U, Krausslich HG. 2000. Human immunodeficiency virus type $1 \mathrm{Vpr}$ protein is incorporated into the virion in significantly smaller amounts than gag and is phosphorylated in infected cells. J Virol 74: 9727-9731.

Murakami T, Freed EO. 2000. Genetic evidence for an interaction between human immunodeficiency virus type 1 matrix and alpha-helix 2 of the gp 41 cytoplasmic tail. $J$ Virol 74: 3548-3554.

Murakami T, Ablan S, Freed EO, Tanaka Y. 2004. Regulation of human immunodeficiency virus type 1 Env-mediated 
W.I. Sundquist and H.-G. Kräusslich

membrane fusion by viral protease activity. $J$ Virol 78: 1026-1031.

Muziol T, Pineda-Molina E, Ravelli RB, Zamborlini A, Usami Y, Gottlinger H, Weissenhorn W. 2006. Structural basis for budding by the ESCRT-III factor CHMP3. Dev Cell 10: 821-830.

Obita T, Saksena S, Ghazi-Tabatabai S, Gill DJ, Perisic O, Emr SD, Williams RL. 2007. Structural basis for selective recognition of ESCRT-III by the AAA ATPase Vps4. Nature 449: 735-739.

Ohishi M, Nakano T, Sakuragi S, Shioda T, Sano K, Sakuragi J. 2011. The relationship between HIV-1 genome RNA dimerization, virion maturation and infectivity. Nucleic Acids Res 39: 3404-3417.

Onafuwa-Nuga AA, Telesnitsky A, King SR. 2006. 7SL RNA, but not the 54-kd signal recognition particle protein, is an abundant component of both infectious HIV-1 and minimal virus-like particles. RNA 12: 542-546.

Ono A. 2009. HIV-1 assembly at the plasma membrane: Gag trafficking and localization. Future Virol 4: 241-257.

Ono A, Freed EO. 2001. Plasma membrane rafts play a critical role in HIV-1 assembly and release. Proc Natl Acad Sci 98: $13925-13930$.

Ono A, Ablan SD, Lockett SJ, Nagashima K, Freed EO. 2004. Phosphatidylinositol $(4,5)$ bisphosphate regulates HIV-1 Gag targeting to the plasma membrane. Proc Natl Acad Sci 101: 14889-14894.

Ott DE. 2008. Cellular proteins detected in HIV-1. Rev Med Virol 18: 159-175.

Parker SD, Hunter E. 2001. Activation of the Mason-Pfizer monkey virus protease within immature capsids in vitro. Proc Natl Acad Sci 98: 14631-14636.

Peel S, Macheboeuf P, Martinelli N, Weissenhorn W. 2011. Divergent pathways lead to ESCRT-III-catalyzed membrane fission. Trends Biochem Sci 36: 199-210.

Pelchen-Matthews A, Kramer B, Marsh M. 2003. Infectious HIV-1 assembles in late endosomes in primary macrophages. J Cell Biol 162: 443-455.

Pettit SC, Moody MD, Wehbie RS, Kaplan AH, Nantermet PV, Klein CA, Swanstrom R. 1994. The p2 domain of human immunodeficiency virus type $1 \mathrm{Gag}$ regulates sequential proteolytic processing and is required to produce fully infectious virions. J Virol 68: 8017-8027.

Phillips DM, Bourinbaiar AS. 1992. Mechanism of HIV spread from lymphocytes to epithelia. Virology 186: 261-273.

Piguet V, Sattentau Q. 2004. Dangerous liaisons at the virological synapse. J Clin Invest 114: 605-610.

Pincetic A, Kuang Z, Seo EJ, Leis J. 2010. The interferoninduced gene ISG15 blocks retrovirus release from cells late in the budding process. J Virol 84: 4725-4736.

Pires R, Hartlieb B, Signor L, Schoehn G, Lata S, Roessle M, Moriscot C, Popov S, Hinz A, Jamin M, et al. 2009. A crescent-shaped ALIX dimer targets ESCRT-III CHMP4 filaments. Structure 17: 843-856.

Popov S, Popova E, Inoue M, Gottlinger HG. 2008. Human immunodeficiency virus type $1 \mathrm{Gag}$ engages the Brol domain of ALIX/AIP1 through the nucleocapsid. J Virol 82: $1389-1398$.

Popov S, Popova E, Inoue M, Gottlinger HG. 2009. Divergent Brol domains share the capacity to bind human immunodeficiency virus type 1 nucleocapsid and to enhance virus-like particle production. J Virol 83: 7185-7193.

Pornillos O, Alam SL, Davis DR, Sundquist WI. 2002. Structure of the Tsg101 UEV domain in complex with the PTAP motif of the HIV-1 p6 protein. Nat Struct Biol 9: 812-817.

Pornillos O, Higginson DS, Stray KM, Fisher RD, Garrus JE, Payne M, He GP, Wang HE, Morham SG, Sundquist WI. 2003. HIV Gag mimics the Tsg101-recruiting activity of the human Hrs protein. J Cell Biol 162: 425-434.

Pornillos O, Ganser-Pornillos BK, Kelly BN, Hua Y, Whitby FG, Stout CD, Sundquist WI, Hill CP, Yeager M. 2009. $\mathrm{X}$-ray structures of the hexameric building block of the HIV capsid. Cell 137: 1282-1292.

Pornillos O, Ganser-Pornillos BK, Yeager M. 2011. Atomic-level modelling of the HIV capsid. Nature 469: 424-427.

Prabu-Jeyabalan M, Nalivaika E, Schiffer CA. 2002. Substrate shape determines specificity of recognition for HIV-1 protease: Analysis of crystal structures of six substrate complexes. Structure 10: 369-381.

Prabu-Jeyabalan M, Nalivaika EA, King NM, Schiffer CA. 2004. Structural basis for coevolution of a human immunodeficiency virus type 1 nucleocapsid-p1 cleavage site with a V82A drug-resistant mutation in viral protease. $J$ Virol 78: 12446-12454.

Rein A. 2010. Nucleic acid chaperone activity of retroviral Gag proteins. RNA Biol 7: 700-705.

Rein A, Datta SA, Jones CP, Musier-Forsyth K. 2011. Diverse interactions of retroviral Gag proteins with RNAs. Trends Biochem Sci 36: 373-380.

Ren X, Hurley JH. 2011. Proline-rich regions and motifs in trafficking: From ESCRT interaction to viral exploitation. Traffic.

Rulli SJ Jr, Hibbert CS, Mirro J, Pederson T, Biswal S, Rein A. 2007. Selective and nonselective packaging of cellular RNAs in retrovirus particles. J Virol 81: 6623-6631.

Saad JS, Miller J, Tai J, Kim A, Ghanam RH, Summers MF. 2006. Structural basis for targeting HIV-1 Gag proteins to the plasma membrane for virus assembly. Proc Natl Acad Sci 103: 11364-11369.

Saad JS, Loeliger E, Luncsford P, Liriano M, Tai J, Kim A, Miller J, Joshi A, Freed EO, Summers MF. 2007. Point mutations in the HIV-1 matrix protein turn off the myristyl switch. J Mol Biol 366: 574-585.

Saad JS, Ablan SD, Ghanam RH, Kim A, Andrews K, Nagashima K, Soheilian F, Freed EO, Summers MF. 2008. Structure of the myristylated human immunodeficiency virus type 2 matrix protein and the role of phosphatidylinositol-(4,5)-bisphosphate in membrane targeting. J Mol Biol 382: 434-447.

Saksena S, Sun J, Chu T, Emr SD. 2007. ESCRTing proteins in the endocytic pathway. Trends Biochem Sci 32: $561-573$.

Saksena S, Wahlman J, Teis D, Johnson AE, Emr SD. 2009. Functional reconstitution of ESCRT-III assembly and disassembly. Cell 136: 97-109.

Scheifele LZ, Garbitt RA, Rhoads JD, Parent LJ. 2002. Nuclear entry and CRM1-dependent nuclear export of 
the Rous sarcoma virus Gag polyprotein. Proc Natl Acad Sci 99: 3944-3949.

Schliephake AW, Rethwilm A. 1994. Nuclear localization of foamy virus Gag precursor protein. J Virol 68: 49464954.

Scott A, Chung HY, Gonciarz-Swiatek M, Hill GC, Whitby FG, Gaspar J, Holton JM, Viswanathan R, Ghaffarian S, Hill CP, et al. 2005. Structural and mechanistic studies of VPS4 proteins. EMBO J 24: 3658-3669.

Sebastian S, Luban J. 2007. The retroviral restriction factor TRIM5alpha. Curr Infect Dis Rep 9: 167-173.

Sherer NM, Mothes W. 2008. Cytonemes and tunneling nanotubules in cell-cell communication and viral pathogenesis. Trends Cell Biol 18: 414-420.

Shestakova A, Hanono A, Drosner S, Curtiss M, Davies BA, Katzmann DJ, Babst M. 2010. Assembly of the AAA ATPase Vps4 on ESCRT-III. Mol Biol Cell 21: 1059-1071.

Skaug B, Chen ZJ. 2010. Emerging role of ISG15 in antiviral immunity. Cell 143: 187-190.

Sol-Foulon N, Sourisseau M, Porrot F, Thoulouze MI, Trouillet C, Nobile C, Blanchet F, di Bartolo V, Noraz N, Taylor N, et al. 2007. ZAP-70 kinase regulates HIV cell-to-cell spread and virological synapse formation. EMBO J 26: 516-526.

Sougrat R, Bartesaghi A, Lifson JD, Bennett AE, Bess JW, Zabransky DJ, Subramaniam S. 2007. Electron tomography of the contact between T cells and SIV/HIV-1: Implications for viral entry. PLoS Pathog 3: e63.

Sowinski S, Jolly C, Berninghausen O, Purbhoo MA, Chauveau A, Kohler K, Oddos S, Eissmann P, Brodsky FM, Hopkins C, et al. 2008. Membrane nanotubes physically connect $\mathrm{T}$ cells over long distances presenting a novel route for HIV-1 transmission. Nat Cell Biol 10: 211-219.

Spriggs S, Garyu L, Connor R, Summers MF. 2008. Potential intra- and intermolecular interactions involving the unique-5' region of the HIV-1 5'-UTR. Biochemistry 47: 13064-13073.

Strack B, Calistri A, Craig S, Popova E, Gottlinger HG 2003. AIP1/ALIX is a binding partner for HIV-1 p6 and EIAV p9 functioning in virus budding. Cell 114: 689-699.

Stuchell-Brereton MD, Skalicky JJ, Kieffer C, Karren MA, Ghaffarian S, Sundquist WI. 2007. ESCRT-III recognition by VPS4 ATPases. Nature 449: 740-744.

Swanstrom R, Wills JW. 1997. Synthesis, assembly, and processing of viral proteins. In Retroviruses (eds. Coffin JM, Hughes SH, Varmus HE). Cold Spring Harbor Press, Cold Spring Harbor, NY.

Tang Y, Winkler U, Freed EO, Torrey TA, Kim W, Li H, Goff SP, Morse HC. 1999. J Virol 73: 10508-10513.

Tang C, Ndassa Y, Summers MF. 2002. Structure of the Nterminal 283-residue fragment of the immature HIV-1 Gag polyprotein. Nat Struct Biol 9: 537-543.

Tang C, Louis JM, Aniana A, Suh JY, Clore GM. 2008. Visualizing transient events in amino-terminal autoprocessing of HIV-1 protease. Nature 455: 693-696.

Teis D, Saksena S, Emr SD. 2008. Ordered assembly of the ESCRT-III complex on endosomes is required to sequester cargo during MVB formation. Dev Cell 15: 578-589.

Ternois F, Sticht J, Duquerroy S, Krausslich HG, Rey FA. 2005. The HIV-1 capsid protein C-terminal domain in complex with a virus assembly inhibitor. Nat Struct Mol Biol 12: 678-682.

Usami Y, Popov S, Popova E, Gottlinger HG. 2008. Efficient and specific rescue of human immunodeficiency virus type 1 budding defects by a Nedd4-like ubiquitin ligase. J Virol 82: 4898-4907.

Usami Y, Popov S, Popova E, Inoue M, Weissenhorn W, Gottlinger H. 2009. The ESCRT pathway and HIV-1 budding. Biochem Soc Trans 37: 181-184.

Vasiliver-Shamis G, Dustin ML, Hioe CE. 2010. HIV-1 virological synapse is not simply a copycat of the immunological synapse. Viruses 2: 1239-1260.

VerPlank L, Bouamr F, LaGrassa TJ, Agresta B, Kikonyogo A Leis J, Carter CA. 2001. Tsg101, a homologue of ubiquitin-conjugating (E2) enzymes, binds the $\mathrm{L}$ domain in HIV type 1 Pr55Gag. Proc Natl Acad Sci 98: 7724-7729.

Vincent O, Rainbow L, Tilburn J, Arst HN Jr, Penalva MA. 2003. YPXL/I is a protein interaction motif recognized by Aspergillus PalA and its human homologue, AIP1/ Alix. Mol Cell Biol 23: 1647-1655.

von Schwedler U, Stray KM, Garrus JE, Sundquist WI. 2003. Functional surfaces of the human immunodeficiency virus type 1 capsid protein. J Virol 77: 5439-5450.

Weiss ER, Popova E, Yamanaka H, Kim HC, Huibregtse JM, Gottlinger H. 2010. Rescue of HIV-1 release by targeting widely divergent NEDD4-type ubiquitin ligases and isolated catalytic HECT domains to Gag. PLoS Pathog 6: e1001107.

Welsch S, Keppler OT, Habermann A, Allespach I, KrijnseLocker J, Krausslich HG. 2007. HIV-1 buds predominantly at the plasma membrane of primary human macrophages. PLoS Pathog 3: e36.

Wilk T, Gross I, Gowen BE, Rutten T, de Haas F, Welker R, Krausslich HG, Boulanger P, Fuller SD. 2001. Organization of immature human immunodeficiency virus type 1. J Virol 75: 759-771.

Wlodawer A, Gustchina A. 2000. Structural and biochemical studies of retroviral proteases. Biochim Biophys Acta 1477: $16-34$.

Wollert T, Wunder C, Lippincott-Schwartz J, Hurley JH. 2009. Membrane scission by the ESCRT-III complex. Nature 458: 172-177.

Wright ER, Schooler JB, Ding HJ, Kieffer C, Fillmore C, Sundquist WI, Jensen GJ. 2007. Electron cryotomography of immature HIV-1 virions reveals the structure of the CA and SP1 Gag shells. EMBO J 26: 2218-2226.

Wyma DJ, Kotov A, Aiken C. 2000. Evidence for a stable interaction of gp41 with Pr55(Gag) in immature human immunodeficiency virus type 1 particles. J Virol 74: 9381-9387.

Wyma DJ, Jiang J, Shi J, Zhou J, Lineberger JE, Miller MD, Aiken C. 2004. Coupling of human immunodeficiency virus type 1 fusion to virion maturation: A novel role of the gp41 cytoplasmic tail. J Virol 78: 3429-3435.

Xiao J, Chen XW, Davies BA, Saltiel AR, Katzmann DJ, Xu Z. 2009. Structural basis of Ist1 function and Ist1-Did2 interaction in the multivesicular body pathway and cytokinesis. Mol Biol Cell 20: 3514-3524.

Yamashita M, Emerman M. 2009. Cellular restriction targeting viral capsids perturbs human immunodeficiency 
W.I. Sundquist and H.-G. Kräusslich

virus type 1 infection of nondividing cells. J Virol 83: 9835-9843.

Yamashita M, Perez O, Hope TJ, Emerman M. 2007. Evidence for direct involvement of the capsid protein in HIV infection of nondividing cells. PLoS Pathog 3: 1502-1510.

Yang D, Hurley JH. 2010. Structural role of the Vps4-Vta1 interface in ESCRT-III recycling. Structure 18: 976-984.

Yu X, Yuan X, McLane MF, Lee TH, Essex M. 1993. Mutations in the cytoplasmic domain of human immunodeficiency virus type 1 transmembrane protein impair the incorporation of Env proteins into mature virions. J Virol 67: 213-221.

Yu Z, Gonciarz MD, Sundquist WI, Hill CP, Jensen GJ. 2008. Cryo-EM structure of dodecameric Vps4p and its 2:1 complex with Vta1p. J Mol Biol 377: 364-377.

Zamborlini A, Usami Y, Radoshitzky SR, Popova E, Palu G, Gottlinger H. 2006. Release of autoinhibition converts
ESCRT-III components into potent inhibitors of HIV-1 budding. Proc Natl Acad Sci 103: 19140-19145.

Zhai Q, Fisher RD, Chung HY, Myszka DG, Sundquist WI, Hill CP. 2008. Structural and functional studies of ALIX interactions with YPX(n)L late domains of HIV-1 and EIAV. Nat Struct Mol Biol 15: 43-49.

Zhai Q, Landesman MB, Robinson H, Sundquist WI, Hill CP. 2011. Identification and structural characterization of the ALIX-binding late domains of simian immunodeficiency virus SIVmac239 and SIVagmTan-1. J Virol 85: 632-637.

Zhang Y, Qian H, Love Z, Barklis E. 1998. Analysis of the assembly function of the human immunodeficiency virus type 1 gag protein nucleocapsid domain. $J$ Virol 72: $1782-1789$.

Zhu P, Liu J, Bess J Jr, Chertova E, Lifson JD, Grise H, Ofek GA, Taylor KA, Roux KH. 2006. Distribution and threedimensional structure of AIDS virus envelope spikes. Nature 441: 847-852. 


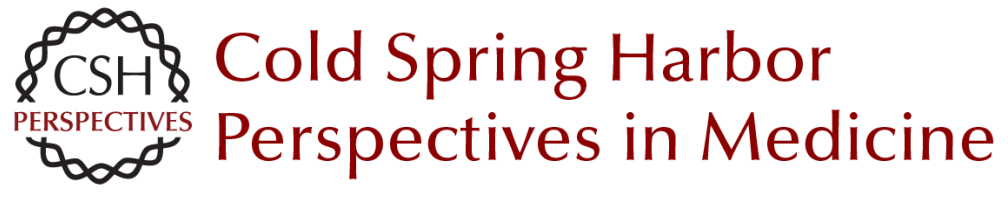

\section{HIV-1 Assembly, Budding, and Maturation}

Wesley I. Sundquist and Hans-Georg Kräusslich

Cold Spring Harb Perspect Med 2012; doi: 10.1101/cshperspect.a006924 originally published online March 13, 2012

\section{Subject Collection HIV}

HIV Pathogenesis: Dynamics and Genetics of

Viral Populations and Infected Cells John Coffin and Ronald Swanstrom

Human Immunodeficiency Virus Vaccine Trials Robert J. O'Connell, Jerome H. Kim, Lawrence Corey, et al.

HIV Transmission George M. Shaw and Eric Hunter

Novel Cell and Gene Therapies for HIV James A. Hoxie and Carl H. June

\section{Behavioral and Biomedical Combination}

Strategies for HIV Prevention Linda-Gail Bekker, Chris Beyrer and Thomas C. Quinn

HIV-1 Assembly, Budding, and Maturation Wesley I. Sundquist and Hans-Georg Kräusslich

HIV-1 Assembly, Budding, and Maturation Wesley I. Sundquist and Hans-Georg Kräusslich

Lessons in Nonhuman Primate Models for AIDS Vaccine Research: From Minefields to Milestones Jeffrey D. Lifson and Nancy L. Haigwood
HIV-1 Pathogenesis: The Virus

Ronald Swanstrom and John Coffin

The T-Cell Response to HIV

Bruce Walker and Andrew McMichael

HIV-1 Reverse Transcription Wei-Shau Hu and Stephen H. Hughes

HIV Pathogenesis: The Host A.A. Lackner, Michael M. Lederman and Benigno Rodriguez

HIV: Cell Binding and Entry Craig B. Wilen, John C. Tilton and Robert W. Doms

Innate Immune Control of HIV Mary Carrington and Galit Alter

HIV DNA Integration

Robert Craigie and Frederic D. Bushman

HIV-1-Related Central Nervous System Disease: Current Issues in Pathogenesis, Diagnosis, and Treatment Serena Spudich and Francisco González-Scarano

For additional articles in this collection, see http://perspectivesinmedicine.cshlp.org/cgi/collection/ 